\title{
FÜHRER DURCH DIE RUINEN VON BAALBEK
}

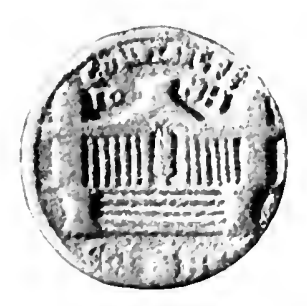

VON PROI. DR. O. PUCIISTEIN

BERLIN $1905 \%$ DRUCK LXI)

VERLAG VON GEOR； REIMER. 


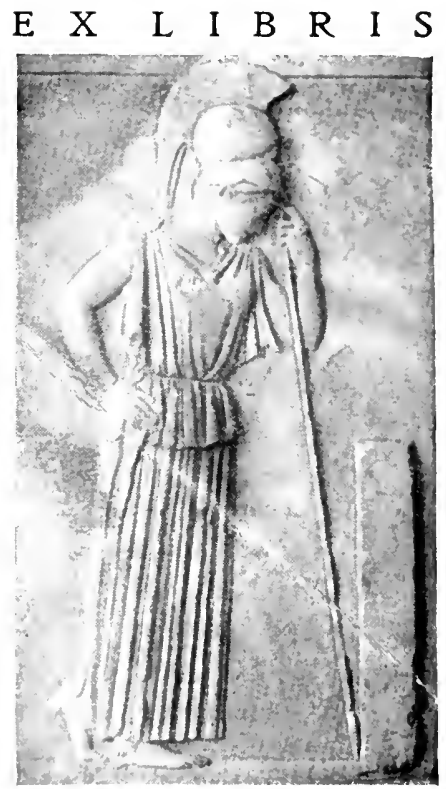

EINAR GJERSTAD 


\section{FÜHRER DURCH DIE RUINEN VON BAALBEK}

\section{VON PROF. DR. O. PUCHSTEIN}

BERLIN $1905 \%$ IDRUCK UND

VERIAG VON GEORG REIMLR. 


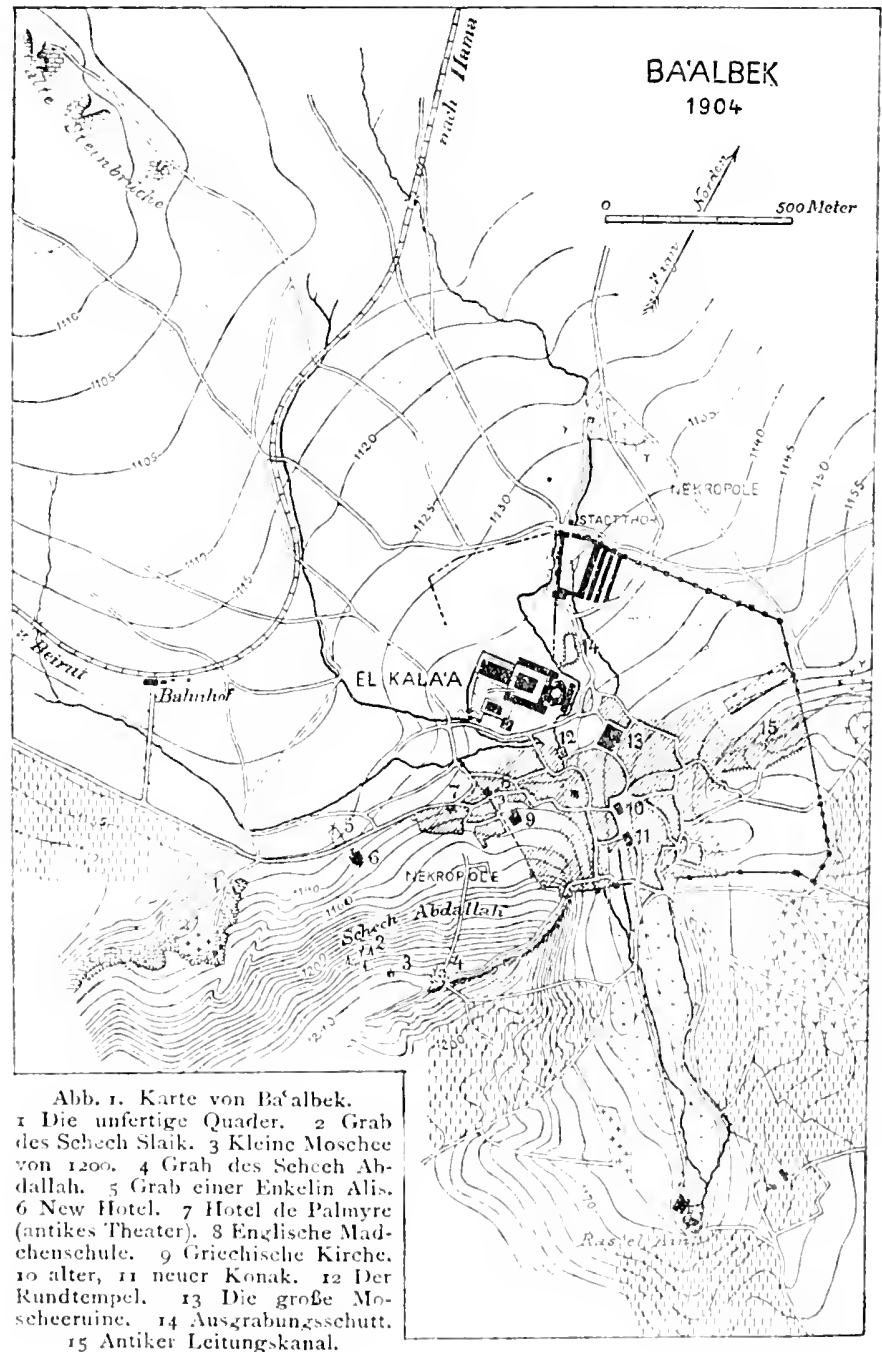




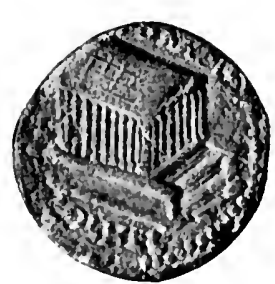

$a$

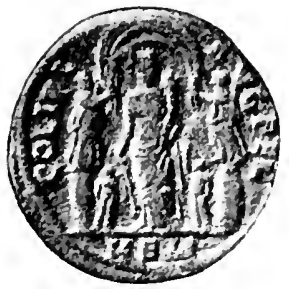

7)

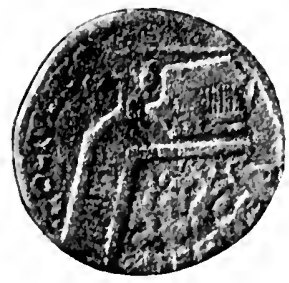

$c$

Abb. 2. Römische Munzen yon La‘albek.

a Der Jupitertempel. $b$ Die Stadtgüttin von Heliopolis. $c$ Ein unbekannter Tempel (auf dum Schech Abdallah?).

Baalbek ist seit dem Sommer Igoz mit der Bahn zu erreichen; man fährt von Rejak, einer Station der Linie Beirut-Damaskus, auf der Zweigbahn, die nach Hama führt, etwa in einer Stunde dahin $(26 \mathrm{~km})$. Der Zug kommt gewöhulich gegen 2 Uhr nachmittags in Ba albek an und die Touristen pflegen es schon wieder am nächsten Tage mit dem Zuge gegen ir Uhr zu verlassen. Es empfiehlt sich jedoch, bis zum übernächsten Tage zu bleiben, so daß man den Cachmittag des Ankunftstages zu einem Spaziergang auf den Schech Abrlallah und durch die Stadt nach Ras el Ain benutzen und dann den Ruinen einen ganzen Tag wirmen kann. Die türkische Regierung erhebt durch einen Pächter ein Fintrittsgeld für den Besuch der Ruinen.

\section{DIE, GESCHICHTE IDER STADT.}

Wir wissen äußerst wenig von den Schicksalen Baalbeks im Altertum. Bedeutung hat es für uns nur durch seinen Götzendienst und durch die grandiosen, äuberst kunstreichen Bauten, die die römischen Kaiser für den heidnischen Kult errichtet haben. Die Stadt war gewib einst von den einheimischen Phöniziern gegründet worden. Aber an die 
orientalische Periode ihrer Geschichte erinnert nur noch der moderne Name, falls er für phönizisch angesehen und als Ba'al der Beka', Herr des fruchtbaren Hochtales zwischen dem Libanon und dem Antilibanon, gedeutet werden darf. Es würde das eigentlich der volkstümliche Name des hier verehrten Gottes gewesen sein. Als dann Alexander d. Gr. den Orient erobert hatte und Syrien unter die Herrschaft seiner Nachfolger gekommen war, siedelten sich auch Griechen in Baabbek an; sie nannten es Heliopolis, Sonnenstadt, da sie den phönizischen Baal mit ihrem Somnengotte Helios identifizierten. Priester des ägyptischen Heliopolis, wo man auch einen Sonnengott verehrte, nahmen daraus Veranlassung, den phönizischen Kult für eine bloße Filiale des ägyptischen $z u$ erklären. Römische Kolonisten scheint Augustus in die Stadt geführt zu haben. Sie behielten den griechischen Namen bei, und nun verbreitete sich von hier aus der $\mathrm{Kult}$ des einheimischen $\mathrm{Ba}$ al über das ganze römische Reich. Da er einen höheren Rang hatte, als der griechischrömische Sonnengott, zog man es vor, ihn Jupiter von Heliopolis zu nemnen, und selbst ein Kaiser, Trajan, holte den Orakelspruch des Gottes ein. Man stellte ihn als einen jungen, bartlosen Mann in langem, panzerartigen Gewande dar, der zwei Stiere neben sich hatte und in der Rechten eine Peitsche schwang, in der linken Blitz und Ähren hielt (vergl. das Titelbild des Bäalbek-Album von O. Puchstein und Th. v. Lüpke und S. I $3 \mathrm{Abb}, 4)$. Zwei andere Gottheiten, Merkur und Venus, diese, wie die große babylonische Göttin, durch eine wenig ehrbare Form ihres Kultes berïchtigt, waren mit Jupiter in demselben Heiligtum vereinigt. Einen neuen, großen und prächtigen Tempel baute der Kaiser Antoninus Pius ( $138-16$ r n. Chr.), und indem seine Nachfolger bis auf Caracalla (2II-21; n. Chr.) die schon von ihm geplanten Höfe und Propyläen zur Ausführung brachten, wurcle für Jupiter und die beiden anderen Götter ein Heilig. tum von seltener Großartigkeit und Vollständigkeit geschaffen. Auch dem Bacchus und der Fortuna (?) errichteten 
die römischen Kaiser Tempel, und es scheint, daß sie sogar die ganze Stadt mit ihren Mauern und öffentlichen Gebäuden von Grund aus neu gebaut haben. Die pompöse Ausführung und die teilweise sehr gute Erhaltung der Tempel gibt uns besser als irgend eine andere Stadt Syriens oder sonst der antiken Welt eine Vorstellung davon, was die römische Baukunst im 2. und 3. Jahrhundert n. Chr. zu leisten vermochte. Das große Heiligtum des Jupiter ist außerdem sehr gut dazu geeignet, uns die alttestamentlichen Berichte über die verschiedenen Teile des Tempels in Jerusalem anschaulich zu machen.

Dem Christentum wurden von den Heiden in $\mathrm{Ba}^{\circ}$ albek auch noch Schwierigkeiten bereitet, nachdem Konstantin d. Gr. (324-337) den Venuskult unterdrückt und eine Bischofsgemeinde gegründet, und Theodosius d. Gr. (379 bis 395) den Haupttempel zerstört und eine Kirche daraus gemacht hatte. Der Zerstörung durch Christenhand war jedoch schon die Natur durch große Erdbeben zuvorgekommen. Man errichtete die Kirche vor der Front des Tempels und setzte sie unmittelbar auf deren Trümmer.

Muhammedanisch wurde Ba'albek im Jahre $6_{34} \mathrm{n}$. Chr. und die arabische Herrschaft dauerte bis I $^{1} 7$, wo die Türken Syrien eroberten. Die zahlreichen Kämpfe der mittelalterlichen Fürsten um den Besitz der Stadt haben wenig Interesse für uns. Wichtig ist jedoch, daß die antike Stadtmauer mit einer geringen Einschränkung beibehalten und je nach Bedürfnis wieder ausgebessert (z. B, 1 I 67 und 13 I 7 ) und schon früh aus den Heiligtümern des Jupiter und des Bacchus eine sehr feste Burg, die Kala'a, hergestellt wurde. Ihre letzte, noch heute wirksame Gestalt erhielt die Burg im 13. Jahrhundert, vor der kirfindung des Pulvers. Viele Teile sind in so gutem Zustande, daß sie uns eine vortreffliche Anschauung von dem arabischen Festungsbau des Mittelalters, von Mauern und Türmen, von Toren und Pforten, von Scharten für Bogen- und für Armbrustschützen, von Zinnen, Pechnasen und Machicoulis gewähren. Daß die 
stadt im I3. Jahrhundert blühend war, bezeugen auch einige Moscheeruinen dieser Zeit.

Heutzutage hat sie etwa 5200 Einwohner (2/5 Mulammedaner, 2/5 Metuali, 1/5 Christen, meist griechisch-katholisch) und blüht sichtlich von neuem auf. Ein Ereignis von großer wissenschaftlicher Bedeutung war es, daß I898 S. Maj. der 1)eutsche Kaiser Wilhelm II. mit Ihrer Maj. der Kaiserin Ba albek besuchte. Unter dem großartigen Eindruck, den die antiken Bauten auf ihn gemacht hatten, bat er $\mathrm{S}$. Maj. den Sultan um die Erlaubnis, die Ruinen ausgraben und genau untersuchen und aufnehmen zu lassen. Das wurcle bereitwillig gewährt, und die umfangreiche Untersuchung rom Herbst 1900 bis zum Frïhjahr igo4 ausgeführt.

\section{TOPOGRAPHIE DER STADT BA}

Einige Minuten vor der Ankunft auf dem Bahnhofe ist rechts ein Grabmal, Qubbet Duris (d. i. die Kuppel des wahen Dorfes Duris), zu sehen, das 1243 aus Stümpfen antiker Granitsäulen gebaut worden ist.

Auf dem Wege vom Bahnhof (1 $120,50 \mathrm{~m}$ ü. d. M.) in die Stadt (durchschnittlich I I $50 \mathrm{~m}$ ü. d. M., bis zum New Hotel, 6 auf der Karte Abb. I, 9 Min., bis zum Hotel de Palmyre (7) I2, bis zur Kala'a i 7 Min.) hat man anfangs einen Blick auf die Westfront der Burg (I in dem BaalbekAlbum). Fr führt am Fuf des Schech Abdallahentlang, eines Rückens (124I m) vor dem Antilibanon, der seinen Namen von dem Grabe dieses Heiligen hat, das oben auf sler Höhe liegt (4). Noch vor dem New Hotel befinden sich süllich von dem Wege große antike Steinbrüche ( 1 , am besten bei der Rückkehr zum Bahnhof zu besuchen); darin überall Spuren der antiken Arbeit, namentlich aber ein kolossater noch nicht fertiger Block (Hadschar el hibla, Stein der Schwangeren, weil er noch am Felsen hängt), der 21,72 m lang und oben ca. 4,30, unten ca. 5,30 hoch und tief ist, also über 500 Kubikmeter Inhalt hat und doch als 
Baustein dienen sollte (vergl. S. 35), obgleich er ein Gewicht von über 1200 Tons gehabt haben würde (XXVIII in dem Album). Hinter dem Stein eine Kapelle des H. Elias.

Steigt man irgendwie auf den Schech Abdallah hinauf, an der Zypresse, die das Grab eines Schech Slāik bezeichnet (3), weiter oben an einer kleinen im Jahre r 200 , z. T. aus antiken Baugliedern errichteten Moschee (3) vorbei, so hat man von oben einen guten Überblick über die Stadt, die Beka' und den Libanon mit dem Daher el Kodib im Norden, dem Sannin und dem Dschebel el Kneise im Süden; weniger wirksam erscheint der Antilibanon, da sein Kamm verdeckt ist. Südöstlich sieht man in einem kleinen Wiesentale die Quelle Ras el Ain; dabei Moscheeruinen des I3. Jahrhunderts und das Landhaus des 1904 verstorbenen Konsuls Lütticke. Das Wasser der Quelle fließt durch die Stadt und bewässert, in viele Kanäle geteilt, die schönen Gärten ringsum. Die moderne Stadt hat sich vom Ostfuß des Schech Abdallah durch das Tal von Ras el Ain bis auf einen niedrigen Hügel im Osten gezogen. Neubauten wie das New Hotel (6), die englische Mädchenschule (8), die griechische Kirche (9), das Haus des Bischofs, das der vornehmen Mutrans, der Serail (Io und ri) u. a. sind an den roten Ziegeldächern kenntlich. Die Burg (II), durch das große Heiligtum der heliopolitanischen Götter - davon die hochragenden sechs Säulen - und den Bacchustempel bestimmt, liegt etwas abseits von dem Berge in die Ebene hinausgeschoben. Südöstlich davon der merkwürdige Rundtempel (I2). In Norden und im Osten kann man auch den Zug der antiken Stadtmauer beobachten, im Norden bis zu dem Komplex verfallener Räume, die zu einer von dem Ägypter Ibrahim Pascha gebauten Kaserne gehören; deren Westhälfte, noch heute benutzt, steht auf dem antiken Nordtor der Stadt. I)ie alte Nekropole erstreckte sich hauptsächlich außerhalb der Nordmauer. Auch der Abhang des Schech Abdallah enthält alte Felsgräber außerhalb der Westmauer der Stadt, die vor der griechischen 
Kirche den Berg heraufstieg; und gleichfalls außerhalb der Mauer lag das antike Theater (unter dem Hotel de Palmyre, 7; sein Hof bedeckt die alte Orchestra, während die rohe Quadermauer an der Straße zu der Rückwand des Bühnengebäudes gehörte).

Wieder hinunter und eventuell durch die Hauptstraße der Stadt zu der Quelle Ras el Ain (vom Hotel de Palmyre 20 Min.), wo bei schönem Wetter das Volk bescheiden Wasser, Wiese und Schatten genießt.

\section{DIE KALA'A.}

(Abb. 11.)

Den Weg zu der Hauptruine findet man leicht. Man muß so gehen, daß man den Rundtempel zur Rechten läßt und an die Ostfront der Burg gelangt. Man berücksichtige schon auf dem Wege, daß man in der Hauptruine von Ba'albek zwar die antiken Bauten, einen Bacchustempel, hoch darüber den Tempel des Jupiter Heliopolitanus, zu dem die 6 großen Säulen gehören, endlich zwei große rings von Bauwerken umgebene Höfe vor sich hat, daß aber alles dies durch Erdbeben, durch Feuer und Menschenhand zerstört und in eine arabische Burg (Kala a) verwandelt worden ist. Daher überall ein Gemisch von antiken und arabischen Teilen, mittelalterliche Zinnen und Pechnasen auf schönem antiken Mauerwerk, Türme und Festungsmauern hinzugefügt und das Ganze von einem (1394 erneuerten) Festungsgraben umzogen.

I)ieser höchst interessante \%ustand der Ruine offenbart sich auf den ersten Blick, wenn man vor ihre Ostfront (III) tritt. Hier befand sich einst der Eingang zu dem Heiligtum der drei großen heliopolitanischen Götter, die sog. Propyläen. Sie waren nach einem altorientalischen Bauschema durch zwei Türme mit einer Säulenhalle dazwischen gebildet (vergl. die Münze auf dem Titelblatt). Man sieht wenigstens noch die r 2 Säulenbasen auf Sockeln, wovon drei 
lateinische Inschriften enthalten; sie besagen, da $B$ a us Privatmitteln zum Heile des Kaisers Caracalla (2 I $1-2 \mathbf{y}$ n. Chr.) drei vergoldete Bronzekapitelle gestiftet worden seien. In dieser \%eit ist also noch an den Propyläen gebaut und damit wohl das ganze Heiligtum vollendet worden. 1)ie kostbaren Kapitelle sind verloren, aber der große Tempel in Palmyra meigt uns noch, wie man in Syrien den bronzenen Blätterschmuck des korinthischen Kapitells um einen Steinkern fügte.

Zu der Säulenhalle hat natürlich einst eine Treppe himaufgeführt. Diese ist aber von den Arabern abgebrochen worden, als sie den Festungsgraben anlegten. Ein schöner Garten hat jetzt seinen Platz eingenommen, wie auch sonst ringsum der Graben in Gärten verwandelt worden ist. Die neue Treppe hat man in Anschluß an die deutschen Ausgrabungen gebaut, in den Maßen der antiken, nur bedeutend selumäler und mit der Straße verbunden. Uber den Säulenbasen hatten die Araber von einem Turm bis zum andern eine Vormaner errichtet; sie ist jetzt bis auf einen geringen Rest, links im Süden, wieder beseitigt worlen. Aber die arabischen Zutaten, Schießscharten und Zimnen auf clem zweiten Geschoß, sind noch an den beiden Türmen erhalten. Die 'lürme (IV.V) waren auch im Altertum zweigeschossig und latten oben dieselbe Pilasterdekoration wie unten.

Schreitet man die Treppe hinauf, so ist clas /iel hinter den Basen und den Säulen, die man sich in der Phantasie darauf ergänzen muß, die kolossale 'Türöffnung. Finst saben 'Türflügel darin, um sie zu verschließen; der Sturz fehlt. Auch dic 'Tür war von den Arabern zugemauert worden, aber die Deutschen haben den ursprünglichen /ustand soviel wic möglich wiederhergestellt. Man beachte auch die beiden kleinen Nebentüren, wovon die im Norden noch vermatuert, die in süden mit einem arabischen 'förtchen versehen ist, dessen Schwelle hoch ïber dem antiken Niveau liegt. J)ic ganze 'Türwand zwischen den Türmen war einst lekoriert Aber die Araber haben alle Zierate abgeschlagen, um den lieinden jeden Stüt»punkt für ein lirklettern der Matern zu 
nehmen. Denn diese Wand bildete die Hauptmauer der arabischen Festung.

Das Antike ist noch an der Front des nördlichen Turmes erhalten. Es war nämlich die lange, offene Säulenhalle, worin man promenieren konnte, bis die Türen geöffnet wurden, rechts und links je durch ein Turmzimmer erweitert. Das im Süden ist eingestürzt (V); im Norden steht wenigstens noch das erste Geschoß, wälrend das zweite von rien Arabern zur Verteidigung des Zwingers zwischen der Vormauer und Hauptmauer erneuert worden ist. Die antike Front des ersten Geschosses bestand aus einer Pfeilerstellung, in dem charakteristischen Geschmack der späteren Kaiserzeit: bauchige Pfeiler mit schönen korinthischen Kapitellen. Nachträglich, aber auch noch in römischer Zeit, hat man zwischen den Pfeilern Bögen errichtet, die oben ein Tabernakel (lateinisch Aedicula, vergleiche die Rückseite des Mittelbogens), und darüber einen Fries mit Guirlanden tragen.

Durch den nachträglichen Einbau ist die Schwelle zu dem Turmzimmer höher zu liegen gekommen. Innen ist (ler Fußboden des Zimmers verschwunden und das Gewölbe, das ihn trug, halb eingestürt. Wie hier sind überall die Bauten an den beiden Höfen des Heiligtums unterwölbt, da sein Fußboden um Treppenhöhe über dem Terrain lag. An den Wänden des Turmzimmers ist die ehemalige Dekoration besser erhalten. Wie man namentlich im Norden sieht, läuft unten ein Sockel herum; dazu denke man sich kleine Säulen, die einst darauf standen und Tabernakel bildeten, indem je zwei Säulen einen Gebälkkropf trugen, der noch an der Wand sitzt. Dann kam noch ein zweites Geschof, von Tabernakeln mit etwas anderen Kröpfen und mit Giebeln oder flachen Bögen. I)iesen Dekorationstypus wird man überall in der Ruine finden, sich aber hier gut klar machen können (vergl. Abb. 3). Hier ist auch schon \% bemerken, daß viele Einzelheiten an dem gewaltigen Baue unfertig geblieben sind. An den Kanten der Quadern sitzt noch die Bosse, die sie beim Versetzen schützen sollte, 
und im Osten hat gar die Wandfäche da, wo eigentlich die Tabernakelsäulchen stehen sollten, ganz clicke Bosse.

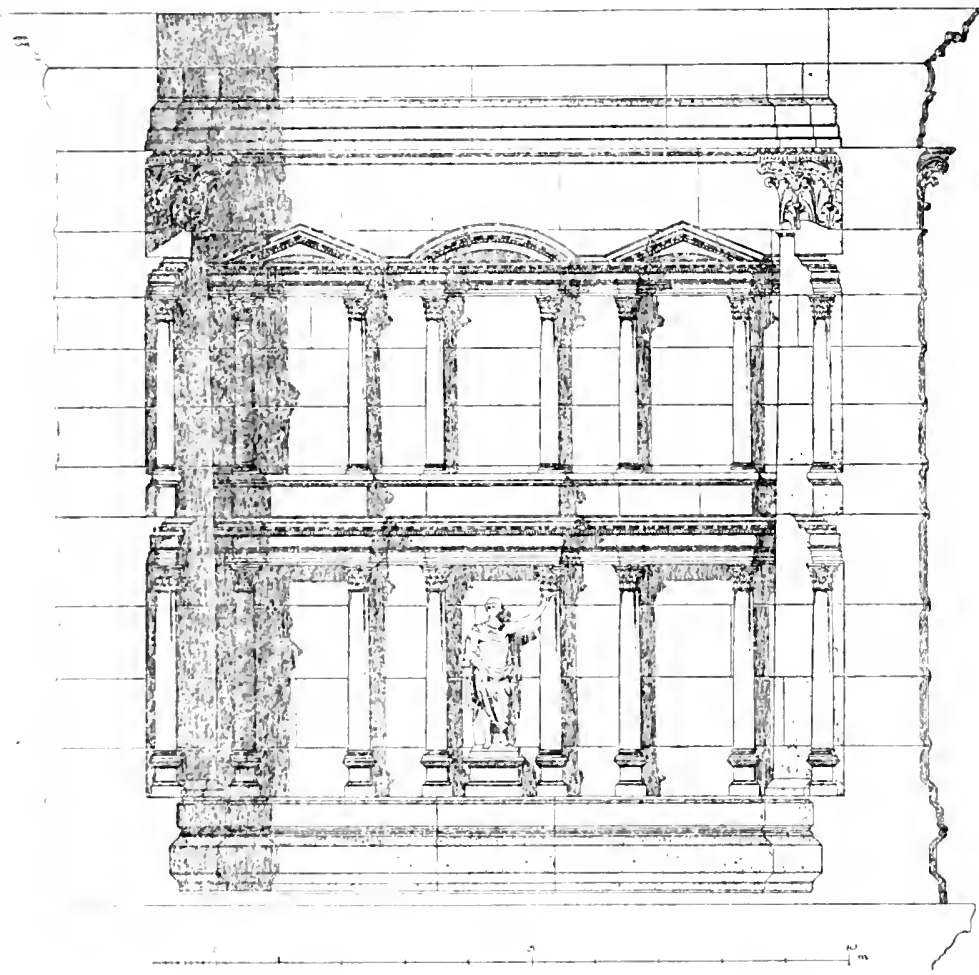

Abb. 3. Die Wanddekoration in Nordturm der Propyläen.

Gehen wir zurück und durch lie große 'Tür weiter in das Innere des Heiligtums, so gelangen wir in einen sechseckigen Hof (VI) und sehen sofort, daß aus diesem geradeatus vor uns eine andere ebenso große und von zwei kfeinen flankierte 'Tür (die rechte Seitentür gut erhalten) wieder 
hinausführt (VII), und zwar in einen zweiten vierechigen Hof. Das ist eine ähnliche Anlage wie bei dem Tempel des Herodes in Jerusalem: die Propyläenhalle könnte dem Vorhof der Heiden entsprechen, der sechseckige Hof dem Vorhof der Juden, den die Heiden nicht betreten durften, der nächste Hof endlich dem Vorhof der Priester mit dem Brandopferaltar.

Wir schauen uns zunächst in dem Sechseck, dem Vorhof des Baalbeker Tempels um. Auf dem freien Platz hat man Trümmer und arabische Steinkugeln zusammengepackt und einige Bäumchen gepflanzt. Er war im Altertum von Säulenhallen umgeben und das Fundament für die Säulen (der Stylobat) mit seinen z. T. noch unfertigen Stufen ist leicht kenntlich; eine Säulenbasis steht noch in der Südwestecke. Hinter den Säulenhallen lagen einst Säle, rechts und links außer den kleinen Zwickelräumen je zwei. Aber sie sind schlecht erhalten und undeutlich, weil die Araber ihre Außenwände direkt zur Verteidigung benutzt hatten, indem sie in zwei Etagen übereinander Schießscharten anlegten und in der unteren Etage des ersten Saales rechts und links Schartenkammern mit spitzbogigen Gewölben bauten. Bei genauerem Zusehen läßt sich bemerken, daß die Außenwände Fenster hatten, bevor die Schießscharten errichtet wurden. Die Fenster waren jedoch nicht antik, vielleicht christlich, und angelegt, als man das Sechseck in eine Zentralkirche, wie sie im 4. Jahrhundert n. Chr., seit Konstantin d. Gr., üblich waren, verwandelte und überdeckte.

Auf dem Stylobat stehen jetzt ein Paar Inschriften, die bei den Ausgrabungen gefunden worden sind und Weihungen an den Jupiter Heliopolitanus enthalten. Eine Darstellung des Gottes selbst (Abb. 4, vergl. oben S. 4) sieht man in dem Raume rechts neben der rechten Seitentür; sie stammt ebenso wie die Säulenbasen und Kapitelle von einem kleinen Rundtempelchen, das einst östlich von Baalbek an der Wasserleitung stand. Man beachte das einfache Mosaik, 


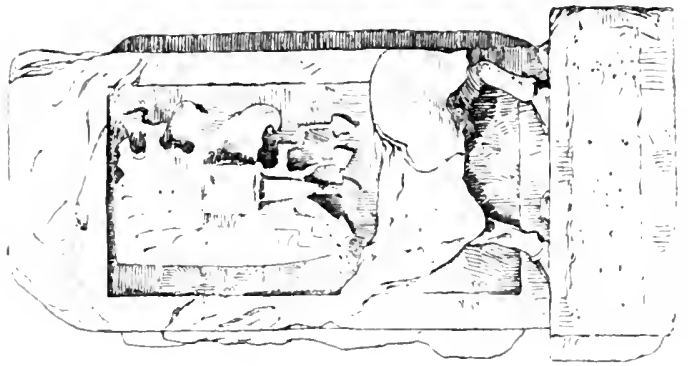

:

岃

$\stackrel{乛}{*}$

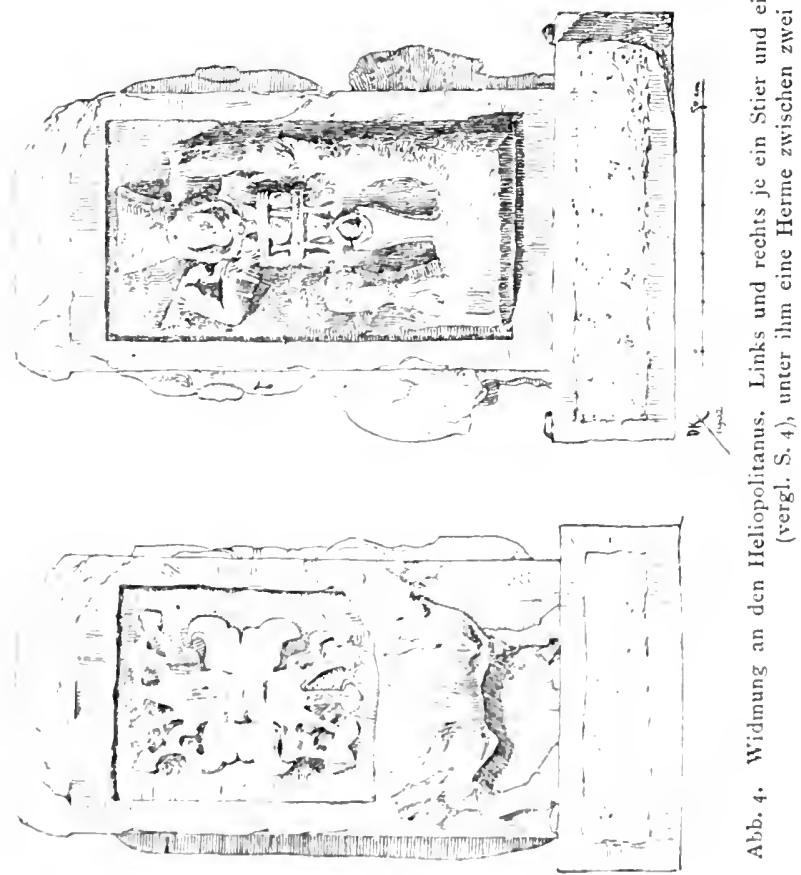


womit die Säulenhallen des Sechsecks ausgestattet waren, während vor dem Hauptportal ein Plattenpflaster liegt. Die Reste der Wanddekoration sind zu gering, als daß man sie betrachtete; (ler nächste Hof bietet mehr davon. Von den Seitentüren führten Treppen zu den ehemaligen Boden- und Dachräumen der Säulenhallen. Die Haupttür ist jetzt frei, aber ron ihrem Aufbau wenig erhalten.

Wir schreiten hindurch und treten in den zweiten, dem Vorhof der Priester entsprechenden Hof (VIII). Infolge ler Zerstörung und der Trümmerhaufen, die ihn bedecken, ist seine Anlage wenig übersichtlich, aber man wird sich leicht orientieren, wenn man berücksichtigt, daß es ein viereckiger von Säulenhallen umgebener Platz war, und wenn man nach dem Jundament für die Säulen und nach den Sälen ausschaut, die hinter den Hallen lagen. Die Mitte des Hofes nimmt eine große christliche, wieder in Trümmer zerfallene Basilika ein (dazu die Stufen im Vordergrund, die an ihrer ehemaligen Ostfront hinaufführten, und der Chor oder die Apsis im Westen); darüber erscheinen links die sechs Säulen des Tempels, der einst im Hintergrund (les Hofes stand (wie auf Abb. I 2), noch weiter links die Säulen eines zweiten außerhalb des Hofes errichteten Tempels, und rechts schließt eine arabische Festungsmauer den Hof im Westen ab.

Von den Einzelheiten wird man zunächst den Säulenhallen und Sälen seine Aufmerksamkeit zuwenden. Die Säulen sind bis auf einige Stümpfe von den Granitschäften verschwunden; doch wird man noeh hier und da auf Säulenbasen aus Kalkstein stoßen, auch auf korinthische Kapitelle, namentlich aber auf viele Bruchstücke von dem Gebälk, das über den Säulen lag, zunächst Architrav und Fries, der mit wunderschönen, fast à jour gearbeiteten Ranken verziert jist (XIV), dann das Gesims mit Zahnschnitt und Konsolen, wovon dic Dachrinne (die Sima) Löwenköpfe als Wasserspeier und mannigfache Blätter und Blüten von virtuoser Ausführung hat. Vor dem Hauptportal, durch das man cin- 
getreten ist, sind auf dem Boden die Keilsteine einer Archivolte zusammengelegt, die hier den geraden Architrav unterbrach. Mehrere Öfnungen im Fußboden der Hallen dienten zur Beleuchtung der Gewölbe im Souterrain (Abb. I2).

Die Säle hinter den Hallen waren auf der Nord- und Südhälfte des Hofes ganz symmetrisch angeordnet. Man betrachtet am besten die nördliche Hälfte. Gleich an das Portal der Ostseite (IX) stößt eine große apsisartige Nische, worin wohl eine Statue gestanden hat. Dann folgt ein Saal, woran man sich die Anlage all der säle klar machen kann: seine Front war nicht geschlossen, sondern mit einer Reihe von Säulen versehen, und die Wände waren wie in den Propyläen mit zweigeschossigen Tabernakeln verziert (die Säulchen alle verschwunden). Über den Tabernakehn hatten sie ein vollständiges Gebälk, Architrav, Fries und Gesims und erst darüber schwebte einst eine flache Holzdecke (die Balkenlöcher zu sehen, wenn man weiter zurücktritt). Derartige säle dienten nicht zum Wohnen, sondern für den Verkehr der Besucher des Heiligtums, namentlich bei schlechtem Wetter, wo man in den Hallen Schutz fand (so wandelte eimmal Jesus zur Winterszeit in Jerusalem in der Halle Salomos. Joh. ıo, 23) und sich die Leute in den Sälen, sei es zur Unterhaltung, sei es zu Geschäften, versammeln konnten. Dieser oder jener Saal mochte auch wie ein Salon Sitze enthalten und dann griechisch als Exëdra bezeichnet werden. I a sich bestimmte Gruppen von Besuchem ihre festen Plätze ausgesucht hatten, zeigen Inschriften wie ,Platz der Kupferschmiede".

In der Nordostecke der Säulenhallen führt rechts eine Tür zu mehreren nicht ausgegrabenen Nebenräumen (hier komnten wic in Jerusalem die Herde zum Kochen und Braten des (Opferfleisches aufgestellt sein, s. Hesckiel 46, 19-24), geradeaus eine andere hochgelegene und ohne Treple nicht $z u$ erreichende Tür in einen Raum, dessen Fußboden eingestürzt ist. Tritt man links davon weiter vor, so sieht man in den Kellerraum hinunter, und auBen erblickt man 
eine große Masse des Schuttes, der aus dem Heiligtum hinausgeschafft worden ist. Man steht hier in dem ersten Saal der Nordseite des Hofes und hat einen arabischen Pfeiler vor sich, der ehemals, nachdem die antike Decke eingestürt war, eine neue, gewölbte Decke trug (wie in Abb. 5). Denn die Araber hatten hier zur Verteidigung ihrer Burg einen Wehrgang mit Zinnen nötig. Bei einem Blick auf die Südseite des Hofes wird man oben auf der antiken Mauer die arabischen Zinnen und unten die Pfeiler erkennen, die einst die Gewölbe unter dem Wehrgang trugen. An der Nordseite, wo wir uns befinden, folgt weiter nach Westen hin einmal ein halbrunder, apsisartiger Saal, worin ein Postament, etwa für die Statuen cler Familie des Caracalla, steht, dann folgt ein sehr großer Mittelsaal (X), noch eine Apsis und endlich wieder ein kleinerer Saal. Hier bietet sich die beste Gelegenheit, die Wanddekoration $\mathrm{zu}$ studieren. Neben der letzten Apsis (XI) sieht man zwischen Vandpfeilern, ähnlich wie in den Propyläen, zweigeschossige 'Tabermakel, unten mit einer runden Nische (von der Muschel im Plafond lateiniscls concha), oben mit einer Aedicula, deren beide Säulchen wieder zu ergänzen sind. Die Concha links hat noch das Postament und die Inschrift für eine Statue bewahrt; es standen hier nämlich überall oder sollten doch Statuen von Stiftern und Göttern stehen, da der Architekt darauf ausging, die Wände, monumentaler und dauerhafter als durch Malerei (wie in Pompeji), mit architektonisch-bildhauerischem Schmucke zu zieren. Diese dekorativen Statuen freilich sind sämtlich verschwunden. Dieselbe ConchenDekoration, z. T. mit reichen Gicbelzieraten, wiederholt sich in der Apsis selbst hinter ihrer zweisäuligen Front, und hier wölbt sich auch noch ein Teil cler Steindecke über (lem Wandgesims. Den anderen Jekorationstypus, einfachere zweigeschossige 'Tabernakel, die je mit den /wischenräumen der Säulen korrespondieren, hat die längswand des letzten Siales; an ihrer Sichmalwand eine geschickte Variation, nämlich wie die Gebälkkröj)fe lehren, eine viersäulige Fron 
mit durchbrochenem Giebel und jederseits davon eine einzelne Säule. Ganz am Ende enthält die Nordseite des Hofes noch einen kleinen Raum, der durch den schönen Tiirrahmen und die Conche oben, wovor einst Säulchen standen, ausgezeichnet ist (XII). Durch ein Loch im Boden blickt man wieder in den Keller unter der Halle.

Der Hof ist hier zu Ende; es war wohl eine Fortsetzung nach Westen hin beabsichtigt, aber sie ist nicht ausgeführt worden, da. sie sich mit einem anderen Projekt kreuzte. Jet»t schließt den Hof eine arabische Festungsmauer ab, die noch bis zu den Zimmen aufrecht steht. Den Wehrgang hinter den Zinnen tragen wiederum P'feiler, und eine zweite Reihe von Schieb. scharten bot zahlreichen Bogenschützen,

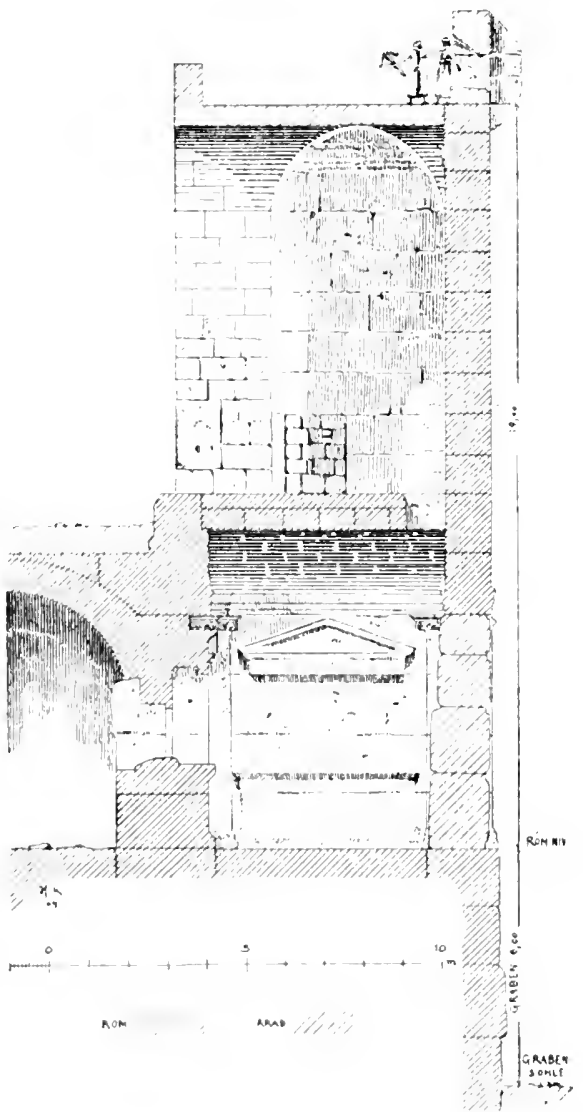

Abb. 5. Her arabische Umbau eines römischen Saales. Uben uber den Cewölbe der Wehrgane mit Zinnen und einer l'echnase. Unten dic antiken Kellersäume, darunter das Fundamens. 
die in den Nischen der Mauer standen, Raum zur Verteidigung. Dicht an der Mauer ein Treppchen zu einem Beobachtungsposten.

Inclem wir auf dem Nord-Stylobat zurückgehen, nehmen wir Gelegenheit den einzigen vollständig erhaltenen Säulenschaft von der Halle zu betrachten: eine monolithe Trommel aus ägyptischem Rosengranit, $7 \mathrm{~m}$ lang und fein poliert. Solcher Granitsäulen standen einst in dem Hofe 84, im Vorhofe 3o, dazu in den Sälen 6o, zusammen r74. Wir steigen nun ostwärts die drei Stufen des Stylobats in den Hof hinunter und wenden uns zu dem Wasserbassin (X). Es ist mit einer nicdrigen, außen bald rund bald eckig geknickten Brüstung eingefaßt, die mit sehr dekorativen, schlecht erhaltenen und $z$. T. auch noch unfertigen Reliefs verziert ist. Eine Wasserrinne lief außen ringsherum und innen stand einst mitten auf dem Mosaikboden ein runder, zierlicher Baldachin und darin sicherlich eine Brunnenfigur. Dies Wasserbecken in dem Hofe vor dem Tempel erimnert an das eherne Meer im Priesterhofe des Tempels von Jerusalem; es wird wie dort zur Reinigung und Lustration derer gedient haben, die dem Gotte opfern oder seinen Tempel betreten wollten, indem sie hier Hände und Füße wuschen.

Nördlich von dem Bassin sind Postamente aufgestellt, die, wie die Inschriften zeigen, einst Kaiserstatuen, und zwar aus Bronze trugen, so der Sabina, einer Tochter des Marc Aurel, des Septimius Severus, des Gordian, auch eines ()ffiziers Velius Rufus (auf den Stufen der Säulenhalle), der anscheinend bereits vor der frbauung des großen Tempels so geehrt worden ist - alle von den römischen Kolonisten in Ba albek gestiftet.

Süllich von dem Bassin haben wir die eine Mauer der Basilika vor uns, mit drei Türen, die jetzt infolge der Ausgrabung hoch über dem römischen Niveau liegen. Die Tonrohrleitungen gehörten zu arabischen Häusern, die jetzt abgebrochen sind. Reste von solchen Häusern befinden 
sich aber noch im Innern der Basilika. Wir wenden uns an die Ostseite derselben und übergehen die Südhälfte des Hofes (hier dieselben Säle wie im Norden, z. 'T. mit reicheren Ornamenten, z. T. noch in dem Zustand vor der Ausgrabung, ferner ein zweites Bassin mit dem Sockel für den Baldachin der Brunnenfigur, endlich in der Südostecke ein verschlossener Raum mit Inschriften und anderen unbedeutenden Fundstüchen). Zur Basilika, ihrem Hauptportal und den beiden Seitentüren (rechts der 'Türsturz aus einem antiken Block von einer $K$ issettendecke gearbeitet) führte eine stattliche Freitreppe hinauf - ungewöhnlicher Weise von Osten her! In der Tat hat man später die Orientierung der christlichen Basilika geändert, hier im Osten einen Chor vor das Hauptportal gebaut und hinten im Westen einen neuen Eingang in die ehemalige Apsis gebrochen. Wir treten in das breite Mittelschiff, das durch Pfeiler von den seitenschiffen getrennt war, und beachten an den Pfeilern die Löcher für die Marmorinkrustation. Sonst hat sich die Basilika in Gegensat\% zu den überreich verzierten heidnischen Bauten durch Einfachheit und Formenarmut ausgezeichnet. Die Reste von arabischen Häusern rechts und links geben eine Vorstellung von dem Schicksal, das dem christlichen Gotteshause nach der Eroberung durch die Araber zuteil geworden. AuBen lehnt sich ein grober Teich, vielleicht der Bestandteil eines arabischen Palastes, an die sïdwand der Basilika. Weiter nach Westen sehen wir im Mittelschiff den Fußboden aufgegraben und die lindamente der Basilikapfeiler freigelegt; das ist wegen des groben heidnischen Brandopteraltars geschehen, der einst von cler christlichen Basiliki überbaut war und nun wie in einer (irube vor uns liegt $(\mathrm{XV})$. Leider ist nur die cine Hälfte des Mtars erhalen, jedoch mit einem reil der Stufen, wo der Priester hinautstieg und dem Bail auf einem Holzstolj die Opferticre verbrannte, nachelem er mit deren Blut den Altar besprengt hatte. Wie die Cisristen den Mlar noch vor der Frbanumg (ler Basilika \%erstörten, sicht man an der Räckscite im 


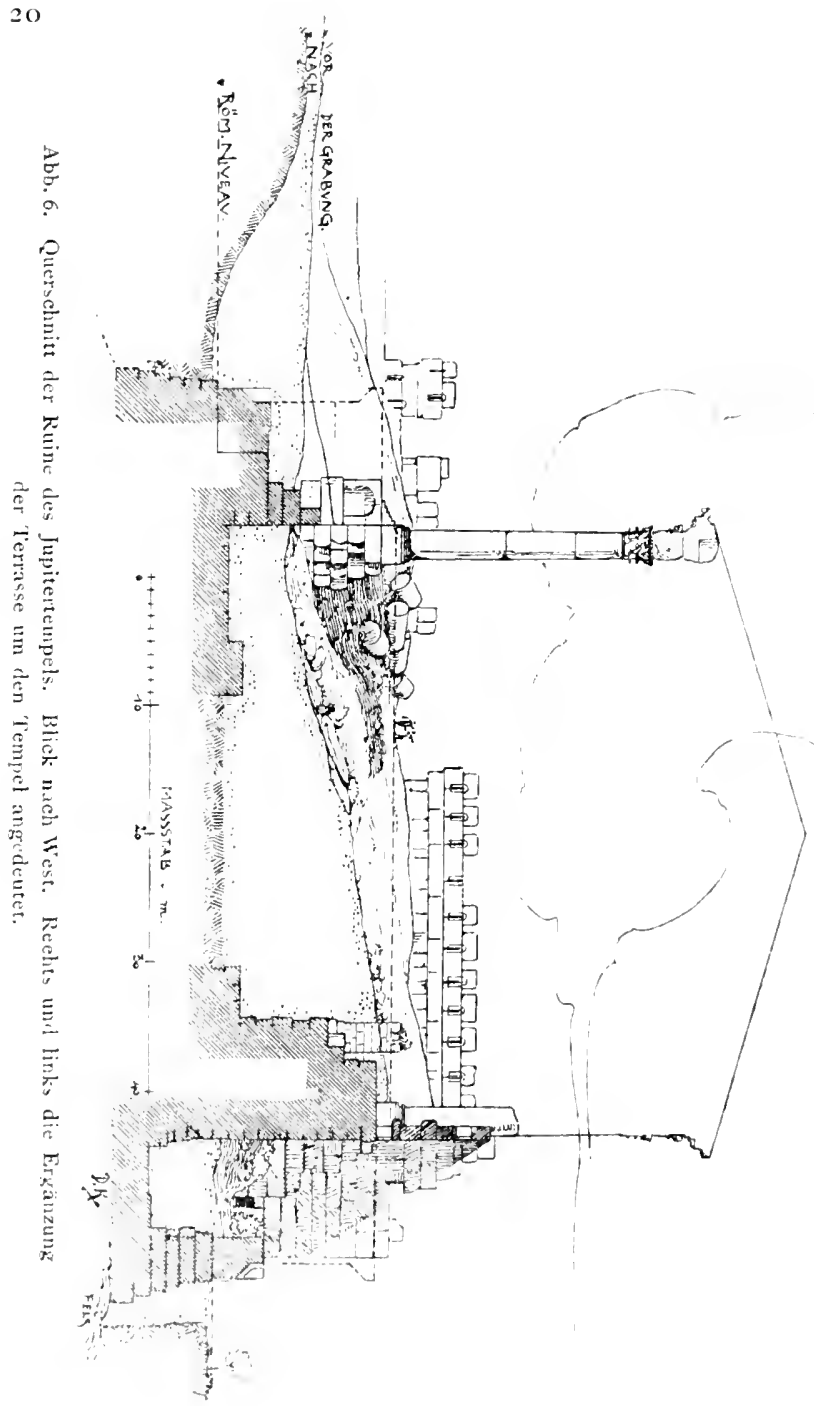


Westen: der eine Stein ist umgestürzt und die Rillen sollten dazu dienen ihn zu zerschlagen.

Man steht hier wieder auf dem antiken Pflaster des Altarhofes, das durch Rinnen nach dem Altar hin abgewässert war, und sieht im Westen die unteren Stufen der großen Freitreppe vor dem Tempel. Uber dessen Trümmern ist einmal die Basilika errichtet worden; daher die zerborstenen Säulen und Kapitelle in ihren Fundamenten. Sie hatte drei Apsiden, eine große in der Mitte und zwei kleinere; durch dic Apsistiir rechts im Norden gelangt man in die gen Osten gerichtete Apsis einer Taufkapelle. Um die Hauptapsis der Basilika amzulegen, hatte man die Tempeltreppe abbrechen müssen. Denn sie führte ursprünglich viel höher hinauf, da der Fußboden des Tempels hoch ïber dem der Kirche lag. Das sehen wir deutlicher, wenn wir durch den nachträglich hergestellten Fingang der Hauptapsis, d. h. durch das Fundament der Frontsäulen des Tempels hindurchschreiten, uns umwenden und auf der Maner die Säulenbasen (einst zehn, noch acht erhalten) und gleich rechts südlich von dem Eingang auch die Fubbodenplatten zwischen zwei Basen erblicken. Wir stehen also $4^{1 / 2} \mathrm{~m}$ unter dem Fubboden, auf einem fundament, desien oberen Teil Byzantiner, Araber und Türken geraubt haben.

Dieser Jempel wat die Hauptanlage des Platzes, angeblich von dem Kaiser Antoninus bius ( $38-$ i6 i n. (hr.), und zwar auf hohem Unterbau errichtet, dimit er in der Ebene weithin sichtbar wäre, und wegen seiner fiöße und seiner Pracht \%u den Weltwublem gerechnet. Das missen wir heute auch noch seinen 'Trimmern \#uerkennen. lir enthielt natïrlich einen Raum (eine Cella) für die statuc des Baal und ringsherum (wie ein Pseudodipteros) eine sehr breite Halle von no Säulen in fler Front und 10 Sïulen an den Langseiten. Aber in welchem traurigen \%ustande ist er auf uns gekommen! Vergl. Abb. 6 und r . (ieht man nach süden his an den Rand des Fundaments, so macht der Anblick der sechs säulen (XVI. X'IJ) dats Schicksal des 
Tempels erst recht begreiflich. V'on den ya Säulen der Südseite ist dies die 11 . his $\mathbf{1 6}$. Die $\mathbf{1}$. bis 10 . ist verschwunden, atuch das fundament, worauf sie standen. Denn dies mußte sich ja von den noch stehenden Sänlen her bis an die front fortsetzen. Sïulenstiumpfe und (iebälkstücke liegen tief unter uns, d. i. an einer Stelle, die auch einmal mit Steinen ausgrefüllt war und eine Terrasse bildete, die bis an den Fuß der anfrechten Süulen reichte. All das fehlende Material ist für jüngere Banten weggeschleppt. Rückwärts, im Norden, sieht man zunächst die arabische festungsmauer mit ihren Zinnen. Darin sterken aber Säulen von der Nordseite des Tempels, und die letzte Säule bildete seine Nordwestecke, so dab man hier die ganze Breite, $47,70 \mathrm{~m}$, und die ganze länge des Tempels, $87,75 \mathrm{~m}$ ohne die Treppe, ermessen kann.

Die Cella innerhalb der Säulen ist über der Erde vollständig verschwunden. Man hat jedoch tief hinuntergegraben und im Norden das äubere Fundament und im Osten das (Querfundiment entdeckt, worauf dic Cellatürwand stand. Am Abstich ist die Aufschüttung zwischen den Fundamenten für den CellafuBboden (davon die oben liegenclen Estricluat\%en) gut zu crkemen.

Wir gehen jetzt zur Nordseite, steigen ïher den Schutt bis zur Höhe der Sïulenbasen und werfen noch einmal einen Blick in die functamentgrube, 10 uns $2 u$ vergegenwïrtigen, wic viel Malterial hier geraubt worden ist. An der Mauer rechts sind dic antiken Säulen leicht von den arabischen Teilen mit den Schicbscharten und Zimnen zu scheiden. ber Wehrgang hinter elen Zinnen ruhte wie immer anf einem verschumblenen Gewölbe. Dic arabisehe Matler ging iber die letzke säule an der Nordwestecke des fempels hinaus mal hog erst weiterhin nach siirlen um, weil der 'Tempel anch im Westen eine Terrasse ror den Säulen hatte und die arabische Maner auf die Vorderkante der Terrasse gesetzt worden ist; von den Säulen der Westfront ist nichts melur vorhanden. Die (versehlossene) Tü̈r nahe der Nord- 
westecke führt in einen arabischen Turm. Er gewährt innen einen schönen Blick auf die Landschaft; auch sielit man von hier gut das erstaunlich hohe Fundament unter den Nordsäulen und davor eine Steinreihe, die erst später verständlich werden wird. Der Zwischenraum wird Muristan, Irrenhaus, genamnt. Im Osten endlich erscheint der Abschluß des Altarhofes von außen, und man sieht deutlich, laß die säle fortgesetzt werden sollten.

Unseren Rundgang fortsetzend steigen wir in die aufgewühlten Schuttmassen hinab und wenden uns gleich rechts, wo wir in dem Spalt das Fundament der verschwundenen Westsäulen sehen. Dahinter begann die Terrasse vor den Säulen. Noch liegt links eine der groben Quadern, woraus sie innen gebaut war, und ganz an Rande treten wir auf einen der drei kolossalen Steine, die wir später von auBen sehen werden (S. 35). I)er schöne Rankenfries stammt aus dem Giebelfeld des Tempels. Zurück und zu den sechs Säulen, dann reclits bis an die arabische Mauer! Auf der Ecke bietet sich ein überraschender Blick auf den zweiten 'Tempel (XVIII) sowie auf die arabischen Festungsmauern, die den größeren mit dem kleineren Tempel verbinden. Vor den sechs Säulen stehen noch drei Basen, deren Säulen erst bei dem Erdbeben ron 1759 umgefallen sind. Der Absatz, den man an den Basen bemerkt, war ehemals durch den Fubboden verdeckt. Die Basisprofile sind noch alle halb unfertig, unfertig auch die Säulen, denn sie sollten noch kanneliert werden, aber ganz vollendet sind die schönen kapitelle und das Gebälk. Blickt man auf das Fundament unter den Säulen (XVII), so leuchtet ein, daB hicr etwas fehit, eben die lerrasse. Sie ist von oben her abgebrochen worden, unten aber noch stehen geblicben, wo sic ron sehr großen Steinen eingefalst wird. So war es auch an der Nordseite (s. oben), nur daß hier die Fiillung geraubt worden ist, die groben steine atuben liegen geblicben sind.

Wir gehen hinter die sechs Säulen zurück und äber das Fundament auf die untere 'lerrasse hinab. I)ie kolos- 
salen Steine außen am Rande sind obenauf noch rauh, zum Zeichen, daß keine anderen Steine darauf gelegen haben, die Terrasse also auch unfertig geblieben war. Ein Gebälkstück zeigt auf dem Friese die kleinen Guirlanden zwischen Stier- und I,öwenköpfen. Von dem Gesims liegt im Osten ganz am Ende links eine brillante Probe; es hat Zahnschnitt, Konsolen und an der Wasserrinne einen Löwenkopf zwischen wundervoll skulpierten Blüten und Akanthusblättern (XIV). $\mathrm{Cu}$ beachten ist auch die daneben auf der Seite liegende Basis: so glatt und sorgfältig waren die Lagerflächen für die Säulen gearbeitet; darin mit Bronze ausgefütterte Dübellöcher und für deren genaue Konstruktion I)urchmesser und hreise fein aufgeschnürt.

\%urück nach Westen zu einem schönen Kapitell, das außerhabb der Terrasse steht. Dann zu dem kolossalen Türsturz von der Basilika mit dem Monogramm Christi und abwärts an die kolossalen Steine der Terrasse von 9,50 $\mathrm{m}$ durchschnittlicher Länge bei einer Höhe von 4,12 $\mathrm{m}$ und einer Dicke von $3,12 \mathrm{~m}$. Wie scharf trotz ihrer Größe ihre Fugen schließen! Da sie ein Zierprofil am Fub erhalten sollten, springt die Fuge oben zurück und alles, was davor sitzt, ist Bosse, die abgemeiBelt werden mïßte. Die l,öcher in dieser Bosse rühren aus dem Steinbruch her. Zum vollständigen Aufbau der Terrasse würde noch eine zweite glatte Steinschicht und eine sichicht mit dem Kopfprofil gehören, endlich oben auch noch einige Stufen, um von der Terrasse in (len Tempel zu gelangen (vergl. Abb. 6).

Wer sich dafür interessiert, mag jetzt die arabischen Befestigungen in der Südwestecke der Burg betrachten. sie sind hier ohne Anlehnung an antike Bauten errichtet. Jicht neben den groben Steinen der Tempelterrasse stehen noch die Pfeiler eines gewölbten Saales, der im Westen an eine fiestungsmauer stiek. Fin Tor führt durcl die Mauer, eng, aler tief, weil die Mauer infolge einer Verstärkung im Westen doppelt ist. Außen gelangen wir nicht gleich ins Freie, sonclern wir haben eine neue, noch spätere Mauer 
vor uns (der Zwischenraum einst überwölbt) und erst die enthält bedeutend tiefer gelegen den Ausgang (das Kupfertor), (lurch die Tür links auf einem innerhalb der Mauer geknickten Wege, der vor der ehemaligen Brücke über den Festungsgraben mündet. Ein eindringender Feind war hier durch zwei schießscharten bedroht. Ein interessantes Verteidigungsmittel ist auch dic unten im Graben mündende Ausfallspforte. Man erreicht sie von innen durch die Tür nördlich von dem Tor, wo eine Treppe hinabführt (Vorsicht!); die Pforte ist verschlossen. Bevor wir durch das obere Tor wieder in das Innere der Burg zurückkehren, beobachten wir noch, wie rechts von ihm im Süden einst ein kleiner Turm vor der älteren (inneren) Mauer vorsprang, wie er vergrößert, damn aber wieder durch die neue Mauer kassiert worden ist. So viel hat man an den Befestigungen gebaut und verändert! I,eider ist die vorderste und stärkste Mauer nicht zu datieren. Im Innern uns nach rechts wendend, gelangen wir an ein zweites älteres Tor, dessen Türsturz (mit einem Kreuz) von einem byzantinischen Baue genommen worden ist. Dieses Tor hatte einst außen jederseits einen kleinen lurm; zuletzt war es aber nur der Zugang zu dem neuen großen Turm, den wir eben von außen sahen. Von der nächsten 'Tür aus ist cler ältere kleine Turm deutlich von dem Vorbaue zu unterscheiden; darin eine Pforte, die einst als Ausfallspforte in den älteren Graben führte und von dem T'urm aus durch eine Falltür zugänglich war. Im süden setzt sich die jüngste Nauer, durch die der Turm kassiert worlen ist, weiter fort. Sie hatte, wie man hier leicht sieht (Abb. 7), unten eine Reihe von Scharten, um den Graben zu beschießsen; darüber eine zweite Reihe, die über den Graben hinausschießen konnte, und ein drittes Geschoß bestand aus einem Gang auf der Mauer, der durch eine Bogentür zugänglich war und außen Sturzscharten (Machicoulis) enthielt (s.S. 34). Endlich ist noch eine vierte Verteidigungslinie zu ergänzen, ein offener Wehrgang mit Zinnen wie sonst überall. Die Decken all der Geschosse 
sind eingestürzt. Diese interessante, sehr starke Mauer endigt im Süden an dem Südwesteckturm der Burg. Hier hat man noch einen Rest einer älteren Mauer, die durch die starke ersetzt wurde, stehen lassen. Die Pforte zwischen ihr und der innersten Mauer führte ursprünglich wiederum in den Graben.

Nun dahin zurück, wo man eingetreten ist. Es ist nicht nötig, rechts hinter der ersten Pforte den Schutt zu erklimmen, noch auch links die junge, arabische Badeanlage zu beachten. Man trete erst durch den nächsten großen Eingang in das Gebäude $z u$ rechter Hand. Es ist die Halle einer großen Moschee, deren Decke einst von Pfeilern getragen wurde. Die Stiitzmauern zwischen den Pfeilem sind modern, damit nicht die großen Trümmer von oben herabstüren. Weiterhin das Bassin zu den religiösen Waschungen, das einst unter freiem Himmel stand, und hinter ihm der Eingang zu der Moschee selbst; geradeaus, unmittelbar an der Festungsmauer, die Gebetsnische (Mihrab), einst inkrustiert und von Säulchen flankiert. Die Pforte rechts führt in das zweite Geschoß des Sïdwestturmes (der Fußboden eingestürt). Die Scharten in dem Turm (vom Jahre I $2 \mathbf{I}_{3}$ ), je drei in einer Nische, sind kleiner als sonst und wohl auf kniende Bogenschützen, nicht auf den Gebrauch der jüngeren Armbrust berechnet. Der'Turm hatte noch ein drittes Geschol und dariber einen Wehrgang.

Aus der Moschee kömnen wir weiter in den Torgang des Sïltores gehen. Dies hat außen zu seiner Verteidigung eine sehr komplizierte Anlage (eine Barbacane) von $129 \mathrm{I}$. Der Weg führte nach links, wo jetzt ein Bretterzaun steht, nicht durch die modern restaurierte Offnung geradeaus, bog lann um und ging (lurch überwölbte Räume zu dem äußeren Tor (vermauert) und zu der Brücke über den Graben. Ringsmm äberall Scharten, die den Zugang zu dem Tore bedrohten. An dem Südwestturm mag man auch die P'forte beobachten, die früher aus seinem Erdgeschoß in den Graben führte, aber beim Ban der Barbacane weiter hinausgeschoben und tiefer gelegt werden inußte (unten geschlossen). 
Zurück zu dem inneren Tor, das wir rechts von den Säulen des Bacchustempels überragt sehen. Der Tempel

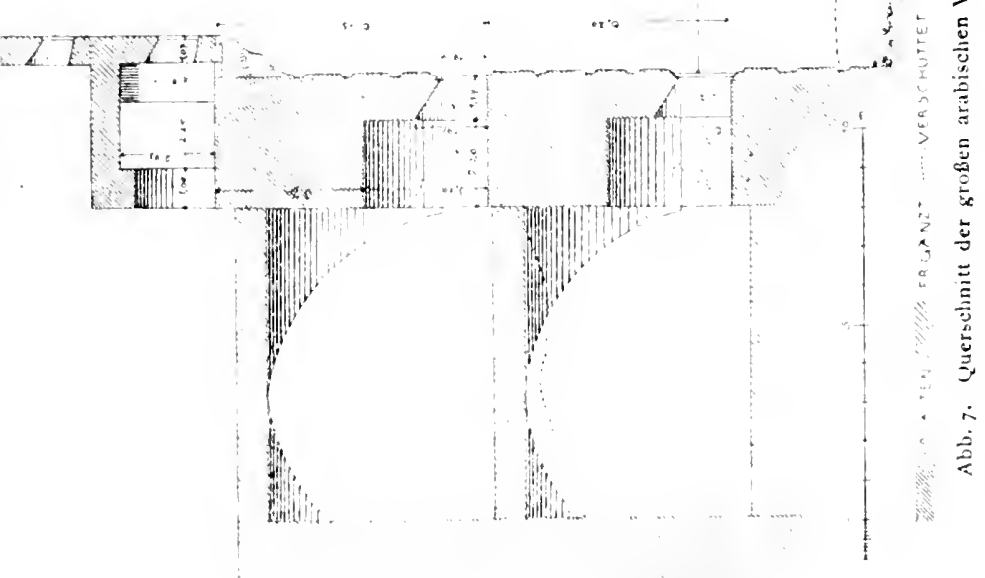

selbst bildete ostwärts die Fortsetzung der Befestigung. An seiner Westfront führte der Weg, ïberwölbt und dunkel, 
geradeaus in die Burg. Da er nicht ausgegraben ist, gehen wir besser - nicht rechts, wo der Fuß des Tempels sichtbar wird - sondern links durch die Moschee zurück, bis wir da, wo die Ecksäule des Tempels hingestürzt ist, das innere Ende des Torweges erkennen. Er mündete in einen Raum, dessen Mittelpfeiler durch ein antikes achtseitiges l'ostiment gebildet wird, und von hier ging es einerseits westwärts in die Burg, andererseits in einen langen einst überdeckten Gang, der zu dem hinaufführte, was oben im Altarhof und im Sechseck lag.

Wir wenden uns nach rechts dem Bacchustempel zu. Er liegt viel tiefer als der große und dessen Höfe und war einst von den Arabern wie ein Bergfried für sich befestigt, daher der Graben $u m$ ihn, und in der Mauer, die vor den Säulen stand, dic Tür hinter einer (verschwundenen) Brücke und die Schiefscharten und das arabische Gemäuer hoch über dem Gesims. Wir gehen geradeaus durch die Trümmerhaufen an die Ostfront des Tempels, betrachten hier aber zunächst wiederum das Arabische. Eine Mauer, wie die grobe im Westen, mit mehreren Verteidigungslinien übereinander, ist quer über die Tempeltreppe von dem Altarhof bis an einen großen Turm im Süden gebant. Eine Pforte dicht neben dem Turm. Es ist ein gewaltiger Eckturm. Schreitet man bis an den Südrand des Tempels (zwischen den ersten Säulen noch Reste der arabischen Mawer), so erkennt man, wie die Schiefscharten des Turmes den breiten Festungsgraben vor dem Tempel beherrschten. In clen Turm führt ein Portal mit einem Stalaktitengewölbe. Die Treppe abwärts gelangt man in dis halbdunkle Erdgeschof, wo dic (iewölbe einerseits auf der antiken Treppenwange ruhen; aufwärts geht es rechts in das schöne und helle Hauptgemach (daran rechts ein Abtritt mit Kuppel iberleckt) und oben auf die Plateform (Vorsicht!). Hier liegen die 'Trümmer des einstigen Machicoulikranzes und im Norken führte eine Tür in die Machicoulis auf der anstoßenten Mauer. Schöner Blick auf dic ganze Umgebung und auf das Gebälk des'lempels (XXIII). 
Zu dem arabischen $A$ ufbau des'Tempels (XIX) wareinst von dem 'Turm eine Brücke geschlagen; er ist nach der Inschrift von dem Sul$\tan$ Kalaun im Jahre $128 z$ erneuert worlen.

Der Gesamtgrundriß der Burg ist jetzt $\mathrm{el}^{\mathrm{*}}$ ledigt. Es erübrigt noch, das besterhaltene und kunstreichste Gebäucle von Báalbek, den kleinen Tempel zu betracliten (Abb. 8); er wurdebisher fälschlichJu. pitertempel genannt, war aber nach

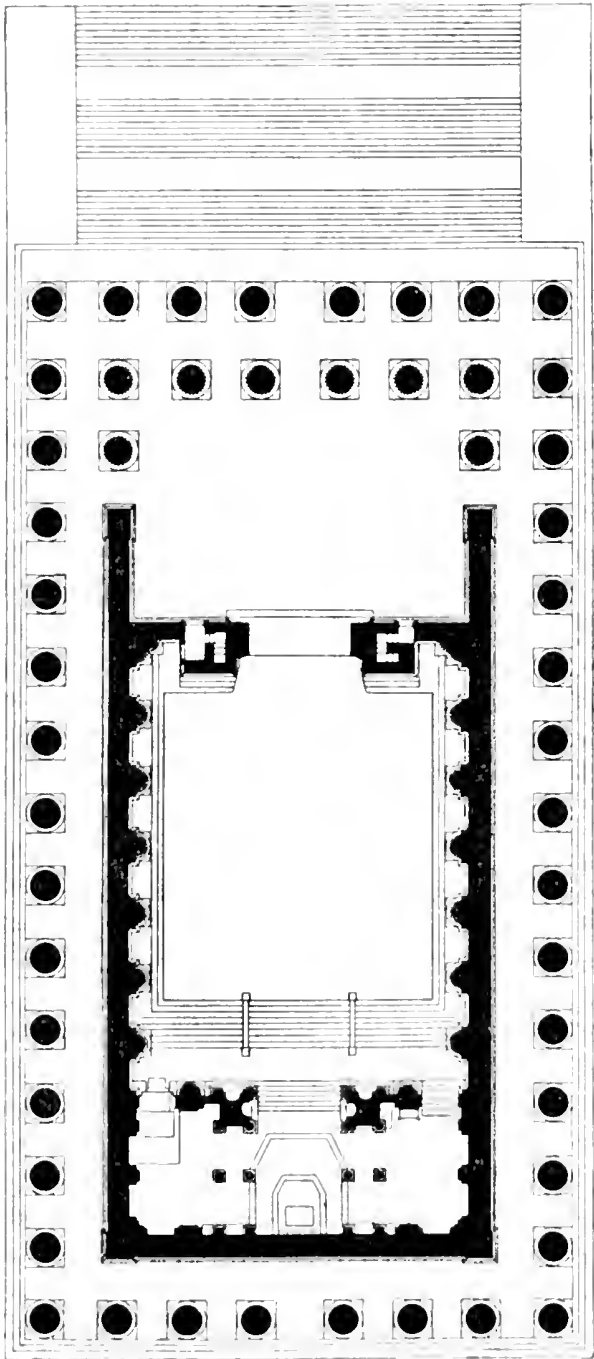


den Resultaten der Ausgrabung dem Bacchus geweilit. Es ist ein sogen. Peripteros, mit einer Halle von 8: I5 Säulen rings um die Cella; er steht auf einem hohen Podium, das man schon gesehen hat. Dies springt wegen der Freitreppe in Osten weit vor. Die Treppe, z. T. durch die arabische Matuer verdeckt, hatte 33 Stufen und drei breitere Absätze. Hinter dem obersten standen einst acht Säulen, dann eine zweite Reihe von sechs Säulen (davon links eine kannelierte und rechts ein Stumpf erhalten), die mit den vorspringenden Wänden (Anten) die Vorhalle der Cella bildeten und ein reichverziertes, schönes Gebälk trugen (XIX. XXII). Vom Fußboden ist nur das Fundament rorhanden. Um die Cellawand läuft unten ein Basisprofil, weiter oben ein Gurt, der einen Figurenfries erhalten sollte; aber nur rechts ist ein Stück davon angefangen und unvollendet geblieben; viel erfreulicher sind links die unglaublich fein und zierlich ausgemeifielten Akanthusblätter und Reben (XXIV).

Eine imposante $\mathrm{T} u ̈ \mathrm{r}(\mathrm{XX})$ fülırt in clie Cella; daneben $z$ wei verschwindend kleine $z u$ den I achtreppen. Es ist die schönste und großartigste Tür aus dem Altertum. Der mittlere Stein des Türsturzes war 1759 gesunken, aber die deutschen Architekten haben ilnn wieder gehoben und der Tür wieder die alte Wirkung verschafft. Auf dem Rahmen in reicher Bildhauerarbeit eine aufsteigende Kette von Bouquets aus $\ddot{h}$ hren und Mohn und ein Geschlinge von Weinund Efeuranken, den Pflanzen des Bacchus. Links am Fuß der kleine von einer Nymphe gesäugte Ciott, und darüber Pan und Satyrn und Bacchantinnen, rechts auch Amoretten, bei der Weinlese. Tierbüsten sitzen in den großen Blumen des Frieses über der Tür und elegante Konsolen tragen das Gesims An der Soffite des Türsturzes schwebt ein Adler und trägt mit zwei Amoretten Guirlanden und in seinen Krallen den Stab des Merkur, des türhütenden Gottes. Ein (iitter und große Flügel verschlossen einst die Tür.

Innen sollen die Trümmer links die brüchige Wand stützen helfen; rechts ist ein Pfeiler auf die Reste von 
Zisternen hingestürzt, die die Araber hier angelegt hatten. Man muß sich diese Trümmer wegdenken und sich vorstellen, daB im Hintergrund auf dem ersten Absatz der Treppe eine ähnliche Dekoration stand, wie an den Längswänden, und daß über den Halbsäulen mit ihrem Gebälk eine flache Holzdecke frei schwebte, dann wird man sich den ursprünglichen Eindruck des großen und prächtigen, durch die kolossale Tür erleuchteten Raumes vergegenwärtigen können. Ganz einzig ist die architektonische Dekoration der Wände (XXI): zwischen den Halbsäulen gewissermaßen Schranken, die von Bögen durchbrochen sind und oben Tabernakel tragen (Säulchen und Statuen dazu fehlen leider auch hier), alle Glieder mit \%. T. sehr schönen Ornamenten übersponnen. An Stelle des einen Tabernakels die Tafel, die der Sultan zum Andenken an den Besuch des deutschen Kaisers und der Kaiserin hat aufstellen lassen.

Während wir uns die Ausstattung des groben Ratumes, worin wir uns befinden, wie des lempels in Jerusalem denken Inüssen, namentlich mit einem Räucheraltar und einem (jpfertisch, enthielt der zweite 'Teil der Cella, das Allerheiligste oder das Adyton, die nur den Priestern zugängliche Kultstatue der Gottheit. Es liegt hoch wie ein Chor in den christlichen Kirchen und die Treppe war mit zwei Geländern versehen (an dem einen drei tanzende Bacchantinnen). Auf dem Absatz der Treppe stand die Adytonfront: wie an den längswänden Halbsäulen (die eine vorniibergestürzt, die andere noch halb aufrecht), seitlich Bögen (der linke liegt unten auf dem Boden mit seinen (Ornamenten), in der Mitte eine große Öffnung, die einst den Baldachin für das Kultbild sehen lieb. Dessen Unterbau war rechts und links von (ler Treppe mit Reliefs verziert, links an eine Rebe gelehnt Bacchus und Ariadne, ringsum das Gefolge des Gottes, rechts das Bacchuskind auf einem P'antherweibchen sitzend, von Bacchanten umtanzt, das Ganze eine Biographic des Gottes, der hier verehrt wurde. Oben im Adyton sicht man an der Rückwand eine Spur von den Stufen des Posta- 
ments, worauf die Statue des Gottes stand, dann eine Basis von rlem Baldachin; zu dem Baldachin gehörten auch die vier kleinen Pilaster an der Rückwand. Ein modernes Loch im Fußboden offenbart die Krypta unter dem Adyton. Man kann im Norden zu ihr hinabsteigen; sie diente wohl als Schatzkammer. Frleuchtet wurde das Adyton durch zwei kleine Fenster in den Seitenwänden.

Zurück zur Cellatür, die innen von den beiden Treppenhäusern flankiert wird; rechts, wo die Wand abgestürzt ist, blickt man in die Wendeltreppe hinein, links ist sie bis oben hin erhalten. Wenn man hinaufsteigt, lasse man sich nicht verleiten, über den Türsturz zu dem arabischen Aufbau zu klettern. Vor der Cellatür ist das Gebälk des Tempels bequem aus der Nähe zu betrachten: ein Fries mit lerselben Dekoration von Stier- und Löwenköpfen wie bei dem großen Tempel und ein Gesims mit sehr tief ausgearbeitetem Eierstab.

Wir gehen in die Südhalle des Tempels und betrachten die hier noch stehenden Säulen, deren eine bei einem Erdbeben umgesunken ist und sich an die Wand lehnt (XXV). Sehr wirksam ist das Ornament der Cassettendecke (XXIII): große Köpfe und Büsten (zuerst eine Meduse, zuletzt ein Silvan) inmitten kleiner Felder. Herabgestürzte Blöcke stehen rechts an der Wand: so eine Stadtgöttin über einem schwimmenclen Flubgott (Antiocheia oder Damaskus), dann eine andere, über der zwei Viktorien ein Segel halten (Heliopolis? vergl. Abb. 2 b), endlich Ganymed von dem Adler geraubt. Iuf den Säulenbasen sind die Dübellöcher mit den Gußrinnen für das geschmolzene Blei etwas anders als bei dem großen 'Tempel. Arabisches Mauerwerk steht noch an der Siidwestecke und in der Westhalle des Tempels; hier noch andere Kassettenblöcke, auf kleineren Bruchstücken Minerva und Venus in der Muschel. Fast die ganze ursprüngliche Wirkung einer Halle hat man im Norlen. I)ie Säulen sind unten zerhackt, weil man das Blei und die Bronzedübel rauben wollte. An der Decke wiederum Stadtgöttinnen, dann 
Diana, Viktoria, auch Alexander d. Gr. mit dem Blitz des Jupiter auf der Hand. Will man eine Darstellung der Derkëto (von Askalon) sehen, muß man zur Front des Tempels zurück und von vorn in die Nordhalle zu dem ersten zerbrochenen Kassettenblock klettern.

Sonst betrachte man hier von außen noch einmal das Podium des Tempels, die Säulen mit den schönen Kapitellen (zwei Typen, die einen mit breit und weich, die anderen mit scharf und tief modellierten Akanthusblättern) und mit dem Gebälk; an der Cellawand oben hinter der dritten Säule von Westen eine interessante Bildung eines Kopfes aus Akanthus (XXIV). Lehrreich wird ein Vergleich der Formen des Bacchustempels mit denen des großen Tempels sein; hier liegt davon ein Kapitell, auch ein Architrav und mehrere Blöcke des Gesimses. An dem großen Tempel ist alles einfacher, klarer und strenger, an dem kleineren alles derber, effektvoller und dekorativer gearbeitet. Er ist jünger als der große Tempel und gehört wie die Propyläen in die Zeit um $200 \mathrm{n}$. Chr.

Endlich bietet sich Gelegenheit, die Keller unter dem Altarhof $z u$ besuchen. Man tritt in den Tunnel unter der Südhalle des Hofes. Er war nur gebaut, damit das Heiligtum ein löheres Niveau erhielt (Abb. I2). Die Seitenwände des Tunnels sind noch roh, aber das Gewölbe sehr schön. Rechts stoßen an den Tunnel die Keller unter den Exĕdren; sie haben z. T. Eingänge von außen her und man hat wohl deren mehrere von der Front des Bacchustempels bemerkt. Diese Keller wurden meist nur als Magazine benutzt, in arabischer Zeit als Pferdeställe. Das Gewölbe des Tunnels hat einige Skulpturen und Inschriften. Da, wo von links der Tunnel unter der Osthalle des Hofes mündet, steigt man eine Holztreppe hinauf und klettert durch ein antikes Fenster in einen schönen exedraartigen Kellerraum, der einmal zu einer christlichen Kapelle eingerichtet worden war. Nach außen hatte er Pfeiler und drei Öffnungen, wovon die seitlichen noch die arabische Vermauerung haben. Die 
Wanddekoration war wie oben, besonders reich und schön an der Rückwand (XIII); die Säulchen der Statuennischen fehlen. liast unversehrt und ohne ihresgleichen ist dic Hach gewölbte Decke, die in ihren Feldem nicht nur Rosetten und Büsten, sondern auch ganze Figuren enthält.

Wenn möglich trete man am Ostende des Tumnels wieder ins Freie, wo man links die rohe $A$ u $B$ nseite des Sechsecks (eine arabische Ausbesserung an der Ecke) und den Propyläenturm sicht. Daß diese Partie verdeckt werden sollte, ist an der Verzahnung der Mauerenden - rechts und bei der Propyläenrückwand - zu erkennen. Wir gehen durch den arabischen Graben, der hier zugeschüttet worden ist, und wenden uns rechts, um die Südhälfte der Ruine von außen zu betrachten. Man wird zunächst über die Gärten hinweg die Front des schönen Kellerraumes und weiterhin vermauerte Türen $z u$ anderen Räumen bemerken. Die Wand hat oben nahe der Ecke Fenster und die arabischen Pechnasen und Zinnen stehen z. T. auf dem antiken Gesims. Etwas weiter gelangt man an den großen arabischen Eckturm und durch eine Gartentür an seine Ostfront. Hinter ihın kommt der Fuß der Treppe des Bacchustempels zum Vorschein; nach dem Brandopferaltar, der hier liegen müßte, haben die Deutschen vergeblich gegraben. Die arabische Mauer auf der Treppe besitzt noch Reste der Machicoulis; so müßte auch die Krone des großen 'Turmes ergänzt werden.

\%urück auf den Weg, der nun an der schönen Südfront des Bacchustempels und dem Tor der Barbacane (XXVI) vorüberführt, wo die Bauinschrift von I 29I eingemauert ist. Der 'Turm an ler Ecke ist von 1213; neben ihm eine P'forte (s. S. 26), oben interessante Reste der Machicoulis. I amn sieht man von der Grabenkante (der Contrescarpe) aus dic jüngste und stärkste festungsmauer mit dem Feld für eint Inschrift und mit den Resten der Machicoulis, weiterhin das Kupfertor. Bei dem Knick hinter dem 'Tor begimnt dann aber eine sehr interessante antike Partic (XXVII). Sie gehört wieder zu der Terrasse um den groben 'lempel: 
unten sind drei Fundamentschichten sichtbar, damn jene großen, 9 m langen Steine von dem Fuß der Terrasse (s. S. 24), hier mit einer Schräge versehen, die zu einem Fußprofil ausgemeißelt werden sollte, darüber jene drei berïhmten, $19,10,19,20$ und $19,56 \mathrm{~m}$ langen, je $4,34 \mathrm{~m}$ hohen und je $3,65 \mathrm{~m}$ tiefen Steine, die das jetzt fehlende Kopfprofil der Terrasse zu tragen hatten; statt dessen haben hier die Araber, z. 'T. aus antiken Werkstücken, eine hohe Mauer errichtet. So kolossale Steine aus dem Steinbruch (s. S. 6) hierher zu transportieren, auf diese Höhe zu heben und so sicher zu versetzen und das alles nur mit Hülfe von Rollen, Hebehn, Winden, Flaschenzägen, schicfen Ebenen und - unendlicher Geduld, ist cine erstamnliche Leistung der römischen (nicht derphönizischen) Ingenieure in Ba albek, womit sie wohl renommieren durften. Auch sonst haben sie ja in der Bewältigung grober Werkstücke bei dem Bau der 'Tempel überall bewundernswertes geleistet und es hat sich noch kein moderner Ingenieur gefunden, der das völlig zu erklären vermöchte. In Baalbek war es Absicht, Steine derselben Gröfe rings um den ganzen Tempel zu legen. Aber das hat man, wie wir sahen (S. 24), (loch nicht ausführen können, so daß der Tempel den griechischen Namen "das Trilithon (1)reistein) erhielt. Der Turm an der Ecke (s. S. 23), worunter der antike Stein abgeschrägt worden ist, stammt von 122.4. Die Nordseite der Burg ist wegen der Gärten nicht zugänglich; wir haben sie von oben gesehen.

\section{I)ER RUNDTEMPLI.}

\section{(Abb. 9).}

Der Zugang zum Rundtempel ist verschlossen; man muß sich den Schlüssel in der Kala a aushitten. Infolge des hohen Sichuttes in der Umgebung ist der Tempel bei der Ausgrabung in eine tiefe und fast zu enge Grube zu liegen gekommen; süllich steht eine Moschee neben ihm. Fis war ein Podhumtempel mit gerader viersïuliger front 
(XXIX), zu der die Treppe auffallenderweise an der Nordseite hinaufführte. Oben stehen rechts noch zwei Säulen-

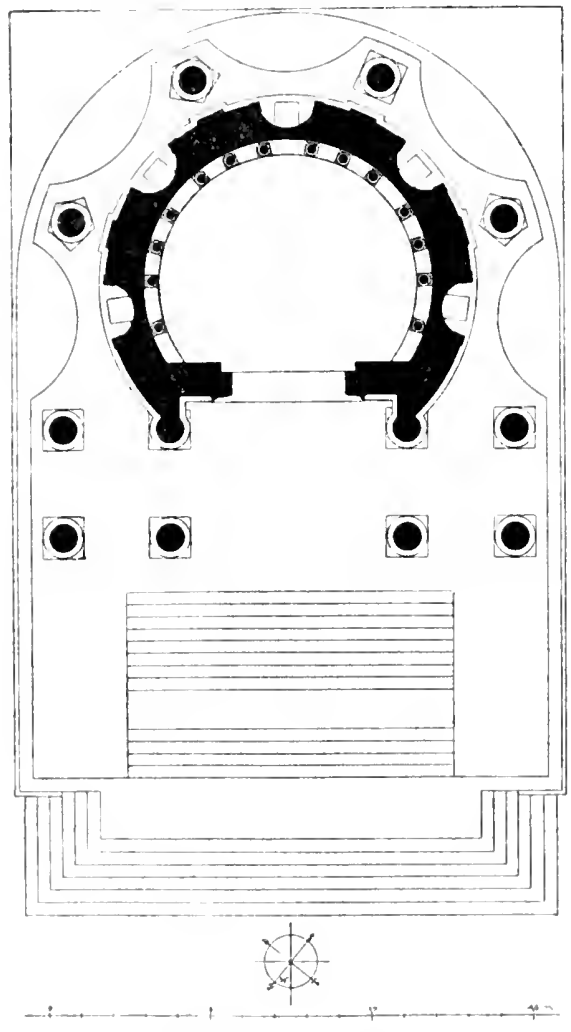

Abb. 9. Der Rundternpel. basen. Die Säulenschäfte, die aus Granit waren, sind verschwunden, ebenso das Gebälk und der Fußboden. Von der zweiten Säulenreihe der Front steht links noch eine Säule mit monolithem Schaft aufrecht. Die Cella hinter der geraden Front ist rund, mit imposanter Tür wie beim Bacchustempel; die kleinen Seitentüren sind im Altertum noch nicht ganz vollendet worden. Die Wanddekoration des Innern besteht wie in dem großen Heiligtum in zweigeschossigen Tabernakeln und einem Hauptgesins. Die Decke war kuppelförmig. Seinen Ruhm als hervorragendes Beispiel der barocken

Tendenzen in der spätrömischen Architektur verdankt der Tempel dem äuBeren Schmuck der runden Cella (XXX). Hier stehen zwar Säulen, aber es ist keine begehbare 
Halle und zwischen den Säulen ist das Podium konkav statt konvex. Ebenso dann auch das Gebälk. Dies zeigt eine Bildung wie das Gebälk des Altarhofes und damit wird der Tempel gleichzeitig sein (um 200 nach Chr.). Sehr beachtenswert sind die fünfeckigen Basen und die fünfeckigen Kapitelle korinthischen Stiles. Pilaster an der Cellawand entsprechen den Säulen; dazwischen wiederum Conchen für Statuen, im Plafond einer Conche eine Büste von zwei Amoretten umflattert. Das Fußprofil des Podium ist nur eine Schräge, $d . h$. in Bosse und unfertig, aber der Steinmetz hatte sich zum Teil schon die Linien eingeritzt, die die einzelnen Teile des Profils bezeichneten. Die Gottheit des Tempels kennt man nicht: man nennt ihn gewöhnlich Venustempel (s. S. 4), könnte ihn indes der Fortuna zuweisen. In neuerer Zeit war es einmal eine Kirche der heiligen Barbara, die jedoch in dem ägyptischen, nicht in dem syrischen Heliopolis den Märtyrertod erlitten hatte.

\section{ANDERE ALTERTÜMER.}

Will man noch andere antike Bauten sehen, so mag man die Chaussee nach Homs, die zu den Propyläen geführt hatte, weiter verfolgen. Sie führt an dem Ausgrabungsschutt vorbei (14); wo sie sich gabelt, geradeaus zu der Kaserne (darin ein kleines Landwehrkommando). Dicht vorher wende man sich nach links und gehe an der byzantinischen oder arabischen Stadtmauer entlang bis zu der Ecke (ro Min.). Hier ist noch ein antiker Turm mit seinem Sockel erhalten, jenseits der Feke im Osten ein zweiter Turm, und beide Hankierten einst ein sehr prächtiges römisches Stadtor (Abb. ro). Die niedrigen Seitenpforten für die Fubgänger lagen dicht neben den Türmen. Das große Haupttor in der Mitte ist von den Arabern kleiner gemacht und in moderner Zeit ganz zugemauert worlen. Zwischen den drei Eingängen standen ehemals auf hohen Sockeln große Säulen, 

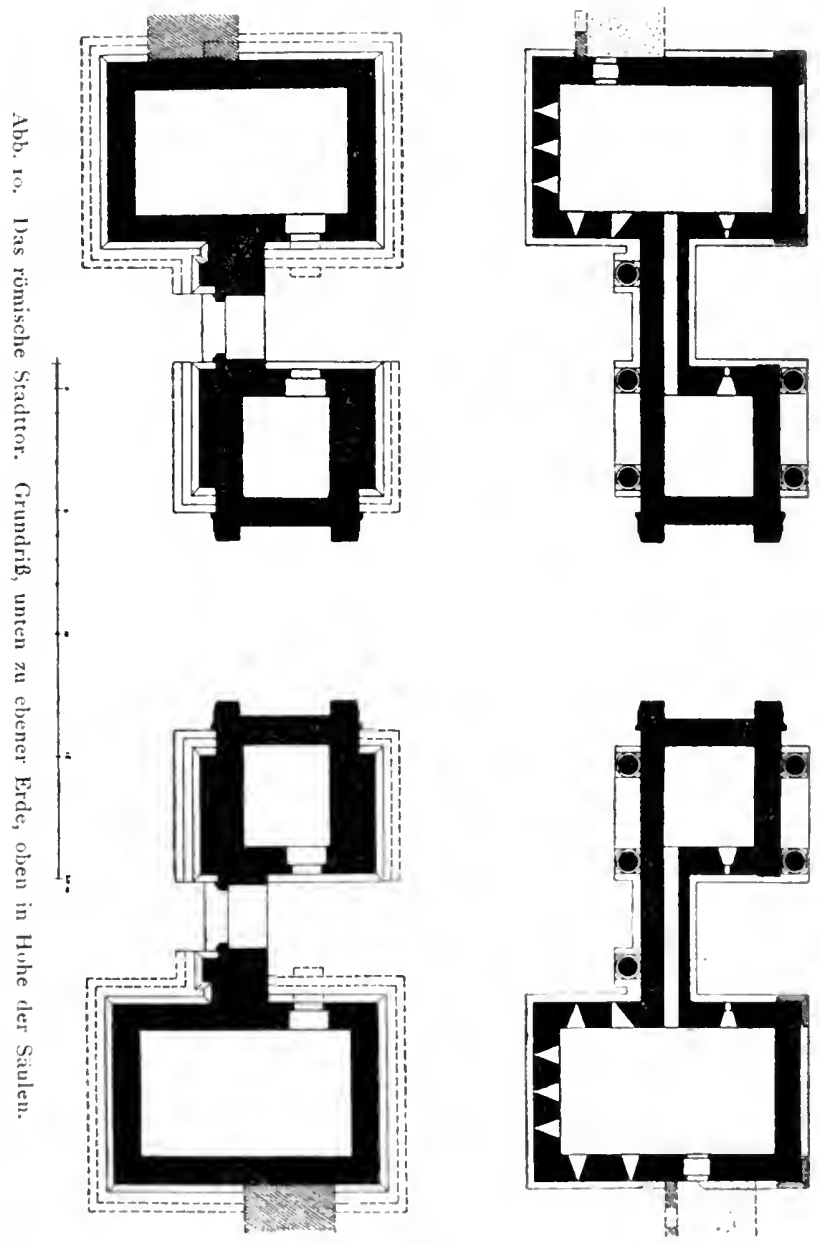
genau in der Art wie die Tabernakel an den Wänden des Heiligtums.

Der muhammedanische friedhof vor dem Tor enthält ein arabisches Mausoleum („die Affenkuppel“) rom Jahre r 409.

Wer nicht gleich wieder umkehren mag, kam längs der antiken Stadtmauer nach Osten gehen $(5 \mathrm{Min}$. bis zur Chaussee). Sie ist zunächst durch die Mauern der modernen Kasernen verdeckt. Dann kommen aber die römischen Türme zum Vorschein. Die Mauerreste jenseits der Chaussee haben nur für Archäologen Interesse; überall da, wo die innere Füllung der Mauer, ihrer Quaderbekleidung beraubt, hoch und sichtbar stehen geblieben ist, waren die Kurtinen dicker als die Partien dicht an den Türmen. Vor der Mauer liegt eine ausgedehnte Nekropole, die leelsgräber enthält.

Auf der Chaussee zurück und bei den Propyläen (ro Min.) geradeaus zu der verfallenen Moschee des i3. Jahrhunderts,

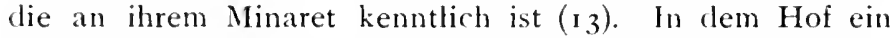
großes Wasserbecken. Die Moschee selbst war sehr ansehnlich; die schönen Granitsäulen und Kapitelle stammen von antiken Bauten, z. 'T. aus dem Heiligtum des Jupiter Heliopolitanus. 
Die wichtigsten Publikationen der Ruinen von Ba'albek.

R. Wood, The ruins of Baalbek. London 1757 .

Cassas, Voyage pittoresque de la Syrie, de la Pbénicie, de la Palestine et de la basse Égypte. Paris 1799.

H. Frauberger, Die Akropolis von Baalbek. Frankfurt a. M. 1892.

O. Puchstein, Br. Schulz, D. Krencker, H. Kohl, Erster und zweiter Jahresbericht über die Ausgrabungen zu Baalbek. Im Jahrbuch des Kass. Deutschen Archäologischen Instituts XVI I90I S. 133-I60, Taf. IV-VII; XVII I902 S. S7-124, Taf. IV-CIX. Vergl, auch im Archäologischen Anzeiger 1904 S. 97 .

Th. Mommsen, Inschrift aus Baalbek. In den Sitzungsberichten der Kgl. Preuß. Akademie d. WViss. I903 S. 817-\$24.

Corpus Inscriptionum Latinarum, III, supplementum, Berlin I902 p. $23 \$ 275 \mathrm{ff}$.

Dr. O. Puchstein und Th. v. Lüpke, Báalbek. 30 Ansichten der deutschen Ausgrabungen. Berlin, Georg Reimer, 1905. 
. 


\section{t5oor.s.

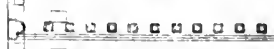
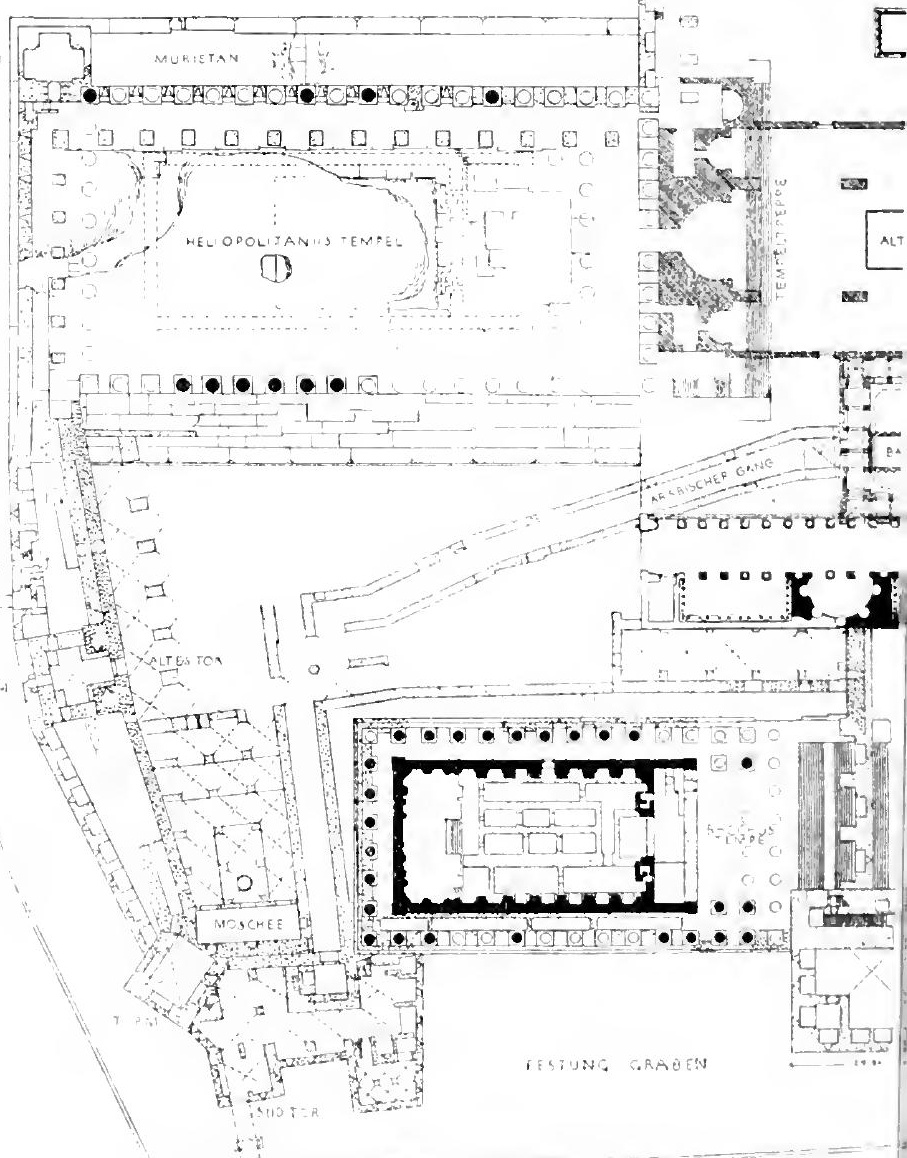


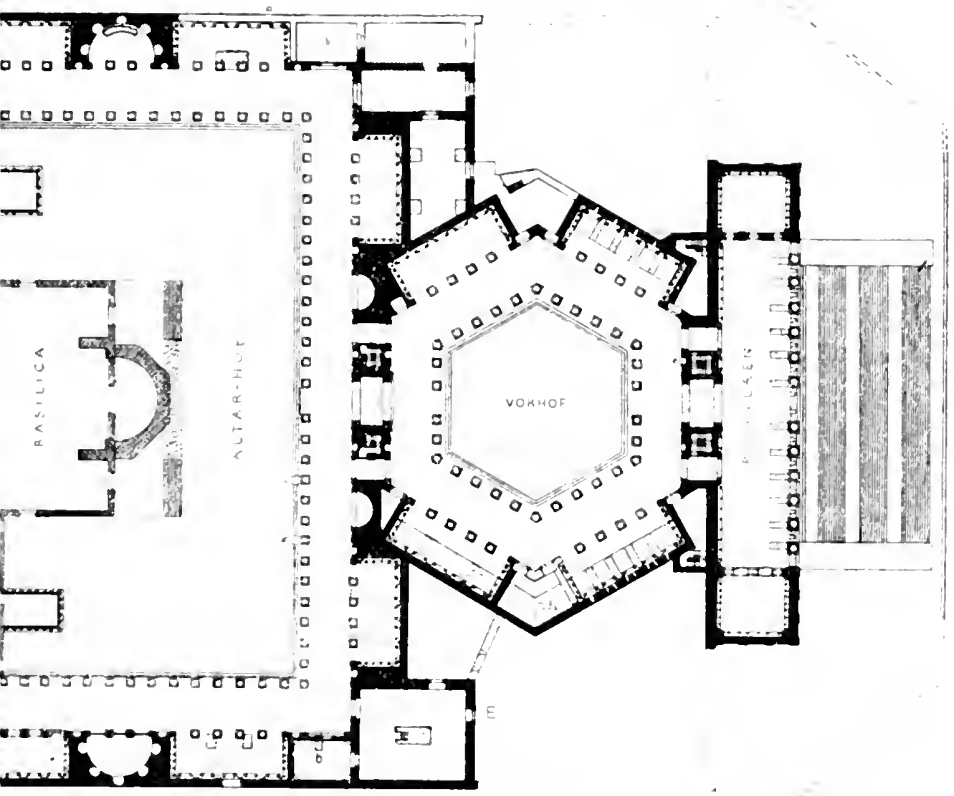

Abb. Ir. Plan der liug von Batabek mit dem gtoßen Heiligtum des Jupiter Heliopolitanus und mit dem liacolasiompel. : : 500. 



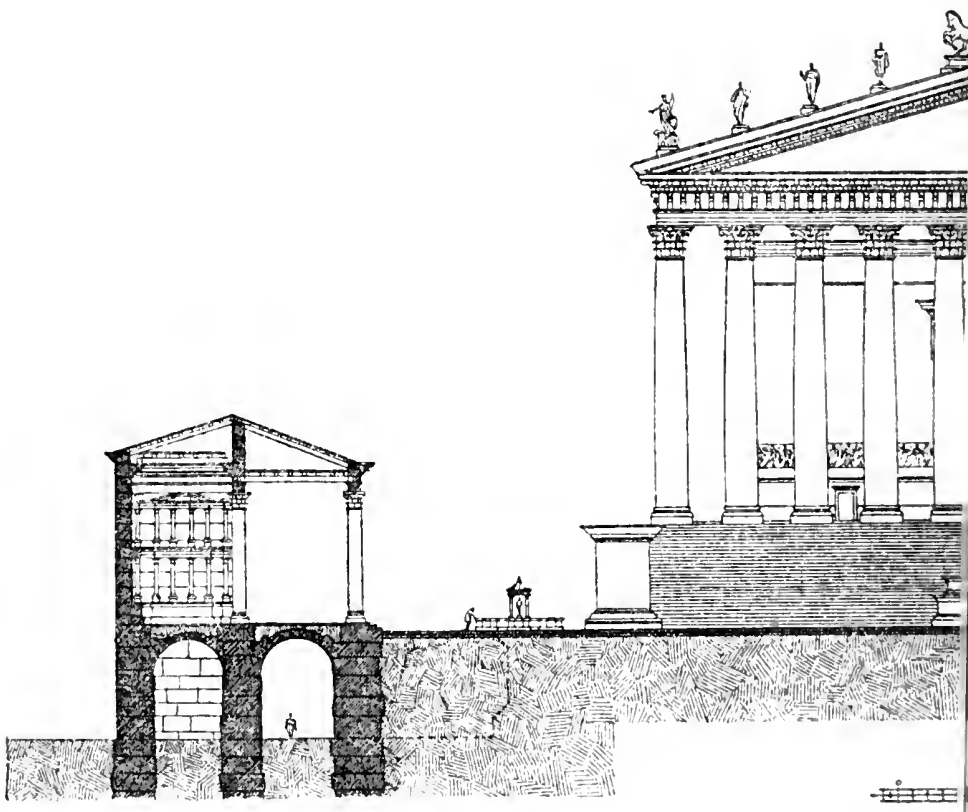

Abb. 12. Querschnitt durc Rechts und links die Saulenhallen und Sale uber den Kell und seitlich die Lustrationsbecken 


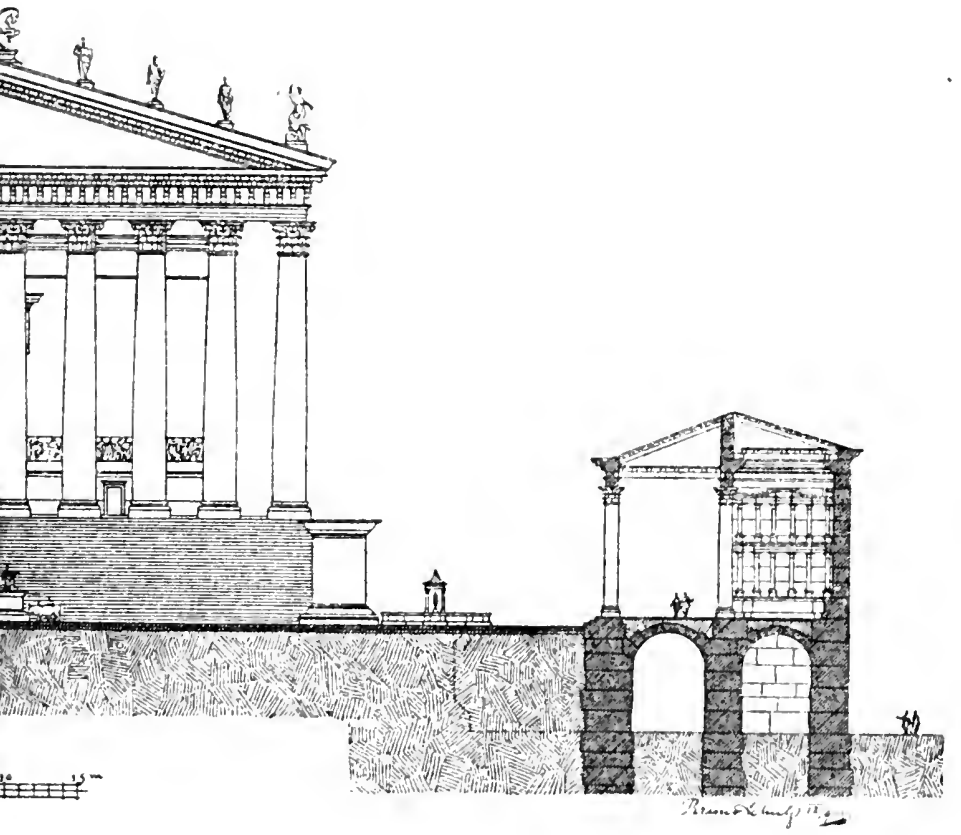

ltarhof des Jupitertempels.

ler Mitte die Front des Tempels, davor der Brandopferaltar

Brunnenfiguren. Rekonstruktion. 


